\title{
TV WARS: EXCLUSIVE CONTENT AND PLATFORM COMPETITION IN PAY TV*
}

\begin{abstract}
Helen Weeds
The article examines incentives for exclusive distribution of premium television programming. Static analysis shows that a vertically integrated operator with premium programming always supplies this content to the rival distributor, using per-subscriber fees to soften competition. In a dynamic setting with switching costs exclusivity confers a market share advantage, benefiting the operator in the future. Under certain conditions this future benefit outweighs the opportunity cost of forgone wholesale fees, making exclusivity the preferred choice. Alternative dynamic mechanisms are explored, identifying essential features. The analysis explains the observed incidence of content exclusivity in pay TV and provides guidance for policy makers.
\end{abstract}

Programme content plays a central role in pay TV competition. In choosing between distributors, consumers base their choice largely on the programming available from each one. ${ }^{1}$ In particular, highly attractive 'premium' programming, especially live coverage of popular sports events and recent Hollywood movies, drives consumer choice. ${ }^{2}$ By making such content available exclusively to its own subscribers, a distributor gains market share from its rivals, making exclusivity potentially attractive as a competitive strategy. For this reason, premium content is often described by regulators and industry commentators as the 'new bottleneck' in broadcasting and new media markets, in place of the traditional local access bottleneck (Ungerer, 2001; Nicita and Rossi, 2008).

Access to premium content has been a major competition concern in the pay TV sector in a number of countries. By its nature, premium content is often monopolised at source (e.g. sports coverage requires televisation rights, which are often sold collectively by the league) or becomes concentrated in the hands of a single pay TV operator (e.g. UK satellite operator BSkyB has for a long time acquired the first-run pay TV movie rights of all six major Hollywood studios, although these sell their rights independently). In the $\mathrm{UK}$, over the past twenty years, there have been repeated investigations into BSkyB's

\footnotetext{
* Corresponding author: Helen Weeds, Department of Economics, University of Essex, Wivenhoe Park, Colchester CO4 3SQ, UK. Email: hfweeds@essex.ac.uk.

The author is grateful to the editor, Rachel Griffith, and two anonymous referees for their valuable comments and suggestions. The author thanks Jerry Hausman, Bruno Jullien, Massimo Motta, Pierre Régibeau, William Rogerson, Nicolas Schutz, Tommaso Valletti and many conference and seminar participants for helpful comments and discussion. The opinions expressed in this paper and any errors are those of the author alone. Financial support from the Economic and Social Research Council under grant no. RES-000-221590 is gratefully acknowledged.

This is an open access article under the terms of the Creative Commons Attribution License, which permits use, distribution and reproduction in any medium, provided the original work is properly cited.

1 According to Ofcom (2007, para. 3.61), content is the element of consumers' TV service that is by far the most often described as 'must have', being cited by $88 \%$ of consumers.

2 At the 1996 annual meeting of News Corporation (which owns 39.1\% of BSkyB) Rupert Murdoch is reported to have described sport as the 'battering ram' of pay TV.
} 
wholesale supply of its premium sports and movie channels to other pay TV distributors. ${ }^{3}$ In 2010, following a three-year investigation, communications regulator Ofcom imposed a wholesale must-offer regulation on BSkyB's premium Sky Sports channels, requiring these to be made available to other distributors at regulated prices (Ofcom, 2010). ${ }^{4}$ Elsewhere in Europe, wholesale must-offer remedies have been imposed on a number of pay TV mergers which created a dominant operator with control over premium content (Sogecable/Vía Digital, Spain 2002; Newscorp/ Telepiù, Italy 2003; CanalSat/TPS, France 2006, 2012). In the US programme access rules, imposed under the 1992 Cable Act, have long required vertically integrated operators to supply their programming to other distributors; a similar approach is applied in Canada's broadcasting distribution regulations under the 1991 Broadcasting Act. Yet, even in North America, access to programming has been a concern in two recent mergers: in Comcast/NBCUniversal (USA 2011) and BCE/Astral Media (Canada 2013) conditions were imposed to reinforce regulations preventing the merged firm from withholding programming from other distributors. Content distribution on newly developed mobile platforms and over the internet - rarely covered by existing regulations, as these apply to traditional 'linear' television only is increasingly an area of concern to regulators.

A crucial question in these investigations concerns the incentive of a vertically integrated operator to withhold its premium programming from rival distributors. While integrated operators claim that they have no incentive to withhold, stressing the benefits to them of wide distribution, regulators tend to adopt the opposite view, imposing conditions to ensure wholesale supply. Yet determining whether such foreclosure is actually taking place - let alone whether it is likely to take place after a proposed merger - is not straightforward. While Ofcom concluded its 2007-10 Pay TV investigation stating that 'Sky is acting on a strategic incentive to restrict supply' (Ofcom, 2010, para. 7.7), the Competition Appeal Tribunal took the opposite view of the empirical evidence, ruling that 'Ofcom's core competition concern (that Sky had deliberately withheld from other retailers wholesale supply of its premium channels) is unfounded' (Competition Appeal Tribunal, 2012, para. 27).

The question of whether a pay TV operator with premium programming has an incentive to withhold this content from rival distributors is at the heart of this article. To address this question, I set up a model of competition between a vertically integrated operator and an unintegrated distributor, where the two distributors are horizontally differentiated, and examine the integrated firm's incentives towards wide or exclusive distribution. Static analysis shows that, in a setting where wholesale supply would be expected to expand demand, the integrated distributor always chooses to supply the rival distributor, using per-subscriber wholesale fees to soften competition

\footnotetext{
3 1994-5: first Office of Fair Trading (OFT) review of BSkyB's wholesale programming supply; 1996: second OFT review; 2001-2: OFT Competition Act investigation; 2007-10: Ofcom Pay TV investigation; 20102: Competition Commission Movies on Pay TV investigation; 2013-4: Ofcom investigation into BSkyB's wholesale supply of Sky Sports 1 and 2 to BT (ongoing at time of writing).

4 In August 2012 Ofcom's competition finding was overturned on appeal at the Competition Appeal Tribunal (CAT). In February 2014 the Court of Appeal upheld an appeal against the CAT's judgement brought by BT and Ofcom; accordingly, at the time of writing, the case has returned to the CAT for further consideration.
} 
and extract revenues. Intuitively, this is because the integrated operator can always find a wholesale contract that makes it more profitable to supply the rival distributor than to foreclose it, taking account of both its gain in wholesale revenue and its loss of retail market share. Adding a dynamic element to competition in the form of a switching cost, exclusive content distribution gives the integrated firm an initial market share advantage that is amplified by dynamic effects. Under certain conditions - for highly attractive programming and less differentiated distributors - the future benefit from gaining market share outweighs the current opportunity cost of forgone wholesale revenues, making exclusivity the preferred choice of the integrated firm. Other possible dynamic mechanisms - platform investment and exclusion - are also outlined. These models highlight the essential feature required for exclusivity: some form of scale effect such that greater asymmetry in market shares raises industry profit.

The analysis explains the observed incidence of exclusive content distribution in pay TV markets across many countries. A puzzling feature of the pay TV sector is the variety of distribution patterns that are observed, even when wholesale arrangements are freely negotiated in the absence of regulation. In many instances, a vertically integrated operator chooses to supply its premium content to rival distributors but in others premium content is supplied exclusively to the operator's own subscribers. Sometimes a mixed pattern is seen in which the operator supplies some rivals but not others. Two broad patterns can be observed, which are explained by this article as follows. First, exclusive content is often seen between operators that compete head-to-head using the same distribution technology (e.g. satellite-to-satellite), especially during a war of attrition, while competing distributors using alternative technologies (e.g. cable) are supplied. The article explains that the low degree of horizontal differentiation and possibility of exclusion makes it desirable to withhold premium content from a similar, satellite-based competitor, while more differentiated distributors that are difficult to exclude (cable) are supplied. Secondly, exclusivity is often employed by emerging platforms: several European telecoms incumbents building internet television (IPTV) platforms have used exclusive content to facilitate their entry into pay TV and to compete against their broadband rivals. For these players, the desire to build market share in the presence of switching costs and sunk investments provides an incentive for exclusive content.

The article has the following lessons for policy makers. While competition cases in the pay TV sector have rested on the claim that an integrated operator has an incentive to withhold its premium content from rival distributors, this article demonstrates that for such a finding to be substantiated a coherent dynamic mechanism must be present. The mechanism must be based on some form of scale effect such that the asymmetry induced by content exclusivity raises industry profit. This principle can be used to evaluate arguments put forward in competition cases (such as Ofcom's Pay TV investigation), providing guidance to regulators. Secondly, welfare analyses in the article show that the welfare effects of exclusivity, and its impacts on consumers, are not straightforward: while exclusivity entails some loss of allocative efficiency, consumers may benefit overall due to more intense price competition and gains from scale effects. However, outcomes can be mixed, with contrasting impacts on different groups of consumers. 
The article's contribution is as follows. Existing literature cannot adequately explain input foreclosure in a setting where a single vertically integrated firm faces horizontally differentiated downstream competitors. While several papers find that foreclosure may arise in markets with two or more suppliers of the upstream input, ${ }^{5}$ in the case of a single upstream supplier (a 'bottleneck'), a foreclosure result is found only when either: wholesale contracting is constrained to take place on the basis of lump sum fees only; or the unintegrated downstream firm is sufficiently inefficient relative to the integrated firm (see literature review below). The article fills this gap by providing an explanation for the observation of exclusivity in a setting where neither of these conditions hold: its finding that exclusivity can arise in a dynamic setting with scale effects is novel.

In the context of pay $\mathrm{TV}$, the article demonstrates the role of exclusive content in a foreclosure strategy and illuminates the circumstances under which exclusivity is likely to arise. The analysis is based on a framework commonly used to model competition in pay TV which captures the main features of the industry. While the model used in the main part of the article has been chosen to minimise vertical contracting inefficiencies, providing a tractable framework for analysis, an Appendix demonstrates that the findings are not driven by this choice. The topic is highly policy-relevant at a time when competition authorities and communications regulators in Europe and elsewhere are grappling with issues of exclusive content distribution, in both pay TV and new media. The article informs these debates. ${ }^{6}$

The relevance of the article is not limited to pay TV. Its messages are relevant to any sector where an upstream input controlled by one operator is required by, or important to, downstream competitors. The analysis can equally be applied to 'killer apps' in computing and video games markets: by retaining exclusivity over important software or popular video games, the platform provider - in this case the producer of the computer (operating) system or games console - boosts its own retail sales at the expense of rivals, which may be beneficial for similar dynamic reasons to those outlined in this article. More generally, the analysis is relevant to any bottleneck situation, such as access to the local loop in telecommunications and broadband markets. The article casts light on the circumstances under which a foreclosure strategy may be chosen in these industries.

Exclusive content distribution in pay TV is the subject of five articles related to this one. Armstrong (1999) analyses incentives of a monopoly upstream provider to supply its premium content exclusively or non-exclusively to pay TV distributors, under lump-sum and per-subscriber fees respectively. Weeds (2014) considers the impact of advertising funding on the distribution choice of a content provider. Harbord and Ottaviani (2001)

\footnotetext{
${ }^{5}$ When two vertically integrated firms consider supplying an unintegrated distributor additional strategic effects are present which tend to increase the likelihood of complete foreclosure. If one integrated operator were to supply the unintegrated distributor then (since prices are strategic complements) the integrated rival would react by cutting its retail price: this effect may be sufficient to overturn the no-foreclosure result. See Hombert et al. (2010, Section 6.2) for an analysis of this situation.

${ }^{6}$ This article (in working paper form) is cited in the Ofcom Pay TV investigation and Competition Commission Movies on Pay TV investigation, and discussed in submissions by interested parties. It is also mentioned in Autorité de la concurrence (2009).
} 
analyse contractual arrangements and competition in pay TV with particular reference to the UK industry. Stennek (2014) assesses the implications of exclusive distribution for investment in programme quality. Hagiu and Lee (2011) examine links between exclusivity and control over retail pricing in a setting where content providers and distributors are vertically separated.

Both Armstrong (1999) and Harbord and Ottaviani (2001) find that, when persubscriber fees may be used, non-exclusivity is the unique outcome. This noforeclosure result for a single upstream firm is echoed in a more general setting by Hombert et al. (2010, Section 6.1) and Madden and Pezzino (2013, Section 3.3). Hombert et al. (2010) explain that complete foreclosure never arises as long as the downstream firm is not too inefficient; Madden and Pezzino note that their foreclosure impossibility result survives even if retail market competition is arbitrarily close to perfect competition. Overturning this no-foreclosure result in a differentiated goods setting with equally efficient distributors is the contribution of this article.

The no-foreclosure result can be understood by reference to the literature on patent licensing: see Katz and Shapiro (1985, 1986), Kamien and Tauman (1986), Jehiel et al. (1996), Segal (1999) and Jehiel and Moldovanu (2000). This literature teaches us that, given sufficient instruments, the licensor chooses the efficient allocation. In Katz and Shapiro (1985), the holder of a cost-reducing innovation chooses whether or not to license this to a downstream rival; when a per-unit charge can be used there is always a licensing agreement which is preferred by both firms to the no-licensing alternative.

While existing literature cannot adequately explain foreclosure by a single upstream supplier, several articles find foreclosure may arise with two or more upstream suppliers: see Salinger (1988), Hart and Tirole (1990), Ordover et al. (1990), Riordan (1998), Choi and Yi (2000), Chen (2001), Chen and Riordan (2007), Ordover and Shaffer (2007), Hombert et al. (2010) and Bourreau et al. (2011); see also the surveys by Rey and Tirole (2007) and Riordan (2008). In an empirical study of competing platforms, Lee (2013) examines the impact of exclusive software in the US videogame industry.

The model of pay TV competition adopted in this article follows the Hotelling-based approach established by Gabszewicz et al. (2001, 2002, 2004), Dukes and Gal-Or (2003), Gal-Or and Dukes (2003), Anderson and Coate (2005) and Peitz and Valletti (2008). These contributions examine a number of issues including content differentiation, advertising intensity and comparisons of welfare under pay TV and free-to-air (advertising financed) television. However, none of these articles considers content exclusivity.

The article is organised as follows. Section 1 sets out a static benchmark model to examine incentives of a vertically integrated operator to supply its premium content to a rival distributor. Section 2 extends the framework to incorporate a switching cost and examines how this dynamic feature affects incentives towards exclusivity. Section 3 explores other dynamic mechanisms - platform investment and exclusion highlighting the important features that generate an incentive for exclusivity. Welfare implications are assessed for the various models. Section 4 draws on the findings to explain empirical observations of exclusivity in pay TV and discusses implications for policy towards content distribution. Section 5 concludes. There are three Appendices: Appendix A presents an alternative Bertrand model supporting the non-exclusivity result of Section 1; Appendices B and C provide further details of the models in Sections 2 and 3 respectively. 


\section{Static Benchmark}

This Section sets out a static benchmark model to investigate incentives of a vertically integrated pay TV operator to supply its premium content to a rival distributor. The analysis is further supported by the alternative Bertrand framework presented in Appendix A.

The integrated firm operates at two stages of the pay TV industry. It produces premium content (which, depending on one's country, may be variously termed a television channel, programme service or network) containing programming that is highly attractive to viewers, such as live coverage of popular sports or recent Hollywood movies. It distributes this premium content, together with other ('basic') programming and possibly other (e.g. telecoms) services, to its own retail consumers. It may also, if it wishes, wholesale its premium content to the rival distributor; i.e. it chooses between exclusive and non-exclusive distribution. The premium content is assumed to be produced by the integrated firm ${ }^{7}$ and has no substitutes, thus the rival distributor cannot create or acquire equally attractive programming from elsewhere. As channel producer, the integrated firm may also sell advertising airtime on the premium channel. If it chooses non-exclusive distribution then, in addition to its own retail revenues, the integrated firm receives wholesale fees from the rival distributor, while its advertising revenues are proportional to the combined audience.

The distributors are assumed to be horizontally differentiated. In pay TV, horizontal differentiation arises from differences in distribution technology (e.g. cable, satellite, IPTV), basic programming (e.g. general entertainment, news, documentaries, dramas) and/or bundled services (e.g. telephony, broadband) offered by the two distributors. Horizontal differentiation implies that the rival distributor serves consumers that the integrated firm finds it difficult to reach; in other words, non-exclusive distribution offers the possibility of demand expansion.

\subsection{The Model}

Following Anderson and Coate (2005) and others, competition in the pay TV industry is modelled as follows. There are two distributors, $i=A, B$, which provide television channels to a population of consumers (viewers). Consumers regard the products of the two distributors as horizontally differentiated. Following Hotelling (1929), consumers are uniformly distributed on the unit interval, while distributors' locations are fixed at each end of the line. ${ }^{8}$ The utility provided by product $i$ is denoted $u_{i}$. The consumer located at $x \in[0,1]$ obtains net utility of $u_{A}-t x$ if she buys from $A$ and $u_{B}-t(1-x)$ if she buys from $\mathrm{B}$, with transport cost $t>0$. The marginal cost of supplying a consumer is zero. ${ }^{9}$

\footnotetext{
7 Channel production may incorporate externally-produced programming (e.g. Hollywood movies) or require televisation rights to be obtained from third parties (e.g. sports leagues). The upstream stage of contracting with rights holders is ignored here but is explored elsewhere: see Weeds (2014).

${ }^{8}$ For a discussion of channel supply in alternative oligopoly models see Harbord and Ottaviani (2001, Section 3.3.1). Appendix A to this article considers the Bertrand model.

${ }^{9}$ Little in the analysis is altered if there is a distribution cost per viewer. It is assumed that any fixed costs are sufficiently small that both distributors continue to operate.
} 
Utility $u_{i}$ is given by $u_{i}=v_{i}-p_{i}$, where $v_{i}$ represents the quality of $i$ s content (taking account of disutility from any advertising carried) and $p_{i}$ is the subscription charge. Quality $v_{i}$ is made up of two components: basic channels, collectively of quality $v_{0}$, and - if the distributor has access to this - premium content $v$. The premium content is produced by distributor $A$ which supplies this to its own subscribers. If it chooses, $A$ may also wholesale its premium content to $B$; the question of whether this supply takes place - i.e. whether non-exclusive or exclusive distribution is chosen - is the subject of this article. It is assumed that the distributors are symmetric ex ante in the sense that $v_{0}$ is identical; $v_{0}$ is assumed to be sufficiently large for the market always to be covered. Thus, the relative quality of the two distributors' products depends crucially upon whether $A$ chooses exclusive or non-exclusive distribution.

The game takes place as follows. At the start, $A$ chooses whether or not to supply its premium content to $B$. If it chooses to do so, $A$ offers the premium content to $B$ in return for a per-subscriber fee, $c,{ }^{10} B$ may either accept or reject the offer. ${ }^{11}$ Distributors then compete in the retail market, simultaneously choosing prices. As channel producer $A$ also earns advertising revenues of $r$ per viewer of the premium content (regardless of distributor). ${ }^{12}$

While providing a tractable framework for analysis and further extensions, the model presented in this subsection has a number of restrictive features. The assumptions of full coverage, preference structure and efficient contracting ensure that under non-exclusive distribution the integrated operator can extract all surplus from both the rival distributor and consumers. To address the potential concern that the finding of this subsection might be driven by these features, undermining its robustness, Appendix A presents an alternative framework based on Bertrand duopoly in differentiated goods which relaxes these restrictions. This alternative analysis demonstrates that, even with downward-sloping demand, incomplete coverage and inefficient contracting, the finding that in static analysis the integrated operator always chooses non-exclusive distribution, which continues to hold.

\subsection{Analysis}

The analysis proceeds as follows. First, retail market outcomes are derived assuming exclusivity and non-exclusivity respectively. Then $A$ 's choice of supply arrangement is determined by comparing its profits under the two scenarios.

When $A$ supplies the premium content exclusively to its own consumers, equilibrium prices and profits are:

\footnotetext{
10 The analysis can alternatively be carried out using a two-part tariff: this allows $A$ to extract additional surplus from $B$ but the findings are qualitatively unchanged.

11 It is assumed that the integrated operator has all the bargaining power in negotiations. While this is convenient and realistic in this setting, alternative approaches could be used. Crawford and Yurukoglu (2012) estimate bargaining parameters in the US pay TV sector.

12 If, instead, advertising airtime is sold by the distributor, outcomes are unchanged: regarding its own subscribers it makes no difference whether $A$ receives advertising revenues as producer or distributor, while (under non-exclusivity) advertising revenues received by $B$ are passed to $A$ via the wholesale fee.
} 


$$
\begin{array}{ll}
p_{A}^{e x c l}=t+\frac{1}{3}(v-2 r) ; & p_{B}^{e x c l}=t-\frac{1}{3}(v+r) ; \\
\pi_{A}^{e x c l}=\frac{1}{18 t}(3 t+v+r)^{2} ; & \pi_{B}^{e x c l}=\frac{1}{18 t}(3 t-v-r)^{2} .
\end{array}
$$

Distributor $A$ gains a larger market share than its rival, with

$$
s_{A}^{e x c l}=\frac{1}{2}+\frac{1}{6 t}(v+r) \text {. }
$$

For the market to remain competitive the following condition is required and is assumed henceforth:

$$
3 t \geq v+r .
$$

The condition requires distributors to be sufficiently differentiated, relative to the attractiveness of premium content, that under exclusivity the distributor without premium content continues to supply some consumers. ${ }^{13}$

When $A$ supplies its premium content to $B$, charging a per-subscriber fee $c$, equilibrium prices are symmetric at $p^{n e}=t+c$ and market shares are one-half each. Profits are then

$$
\pi_{A}^{n e}=\frac{1}{2} t+c+r ; \quad \pi_{B}^{n e}=\frac{1}{2} t .
$$

Note that the per-subscriber fee $c$ is passed on in full to consumers, thus $B$ 's profit is independent of $c$. Since $\pi_{A}^{n e}$ is strictly increasing in $c, A$ would like to raise $c$ as high as possible. It is a dominant strategy for $B$ to accept any contract with a per-subscriber fee up to $v$ but to reject anything higher than this. ${ }^{14}$ Thus, $A$ offers and $B$ accepts a contract with per-subscriber fee equal to $v$. Equilibrium retail prices for each are then $p^{n e}=t+v$ and $A$ 's profit is

$$
\pi_{A}^{n e}=\frac{1}{2} t+v+r
$$

From (1) and (3), A's gain from exclusivity as compared with non-exclusivity, $G_{0} \equiv \pi_{A}^{e x c l}-\pi_{A}^{n e}$, is given by

$$
G_{0}=-\frac{1}{18 t}(v+r)(12 t-v-r)<0
$$

Thus, A finds exclusivity less profitable than non-exclusivity. This gives us the first proposition.

Proposition 1 (Static equilibrium). In the static model, the vertically integrated pay TV distributor with premium content always chooses to supply this content to the rival distributor.

13 The 'competitiveness' condition is imposed for convenience only: if it were relaxed, an outcome may arise in which $A$ supplies the entire market, requiring the analysis to be extended to corner solutions, but the main insights of the model would go through.

${ }^{14}$ If $c>v, B$ would make higher profit by refusing to purchase the premium content from $A$ and instead cutting its price by $v$. It is assumed that $A$ cannot contractually require carriage and specify retail prices (resale price maintenance is illegal in most antitrust jurisdictions). Otherwise, it might be possible to use such a contract to raise retail prices collusively, extracting part or all of $v_{0}$ from consumers. This would also require a lump sum payment to compensate $B$ (e.g. a two-part tariff with a negative fixed term $F$ ).

(C) 2014 The Authors.

The Economic Journal published by John Wiley \& Sons Ltd on behalf of Royal Economic Society. 
Compared with non-exclusivity, exclusivity imposes two opportunity costs on integrated operator $A$ : forgone wholesale fees from $B$ and smaller advertising revenues due to reduced audience reach. The analysis shows that these costs exceed $A$ 's benefit from exclusive distribution of its premium content, which gives it a larger retail market share and higher retail price. The result holds even in the absence of advertising revenues (i.e. when $r=0$ ); with advertising, it is even stronger. Thus, in the static benchmark, it is never rational for the integrated operator to withhold its premium content from the rival distributor.

It can readily be shown that $G_{0}$ is decreasing in its three arguments, $t, v$ and $r$. Intuitively, the comparative static results can be explained as follows.

- With greater horizontal differentiation, $A$ finds it harder to win subscribers from its rival, reducing its ability to replace forgone wholesale business with direct retail sales.

- For more valuable content, the opportunity cost of forgone wholesale fees is higher.

- Greater advertising revenue per viewer raises the opportunity cost of reduced reach.

Defined as the (unweighted) sum of consumer and producer surplus, social welfare under non-exclusivity is given by $W_{0}^{n e}=v_{0}+v+r-t / 4$. Welfare is higher under non-exclusive than exclusive distribution by an amount ${ }^{15}$

$$
\Delta W_{0}=\frac{1}{36 t}(v+r)[18 t-5(v+r)]>0 .
$$

This outcome can be explained intuitively as follows. Non-exclusivity is allocatively efficient in two distinct ways: all consumers with positive willingness to pay receive the premium content regardless of their choice of distributor ${ }^{16}$ and, since each consumer chooses the closest distributor, transport costs are minimised. However, the benefit of non-exclusivity to consumers is limited because the per-subscriber fee sets a floor beneath retail prices: despite the appearance of retail competition, the supply of premium content is effectively monopolised. In fact, consumers would be better off under exclusivity - despite allocative inefficiency - as they would then benefit from stronger price competition. Compared with exclusivity, consumer surplus is lower under non-exclusivity with the difference given by ${ }^{17}$

\footnotetext{
${ }^{15}$ Welfare results are sensitive to the assumption that firms are initially symmetric. Allowing for asymmetric firms, Harbord and Ottaviani (2001) find non-exclusivity to be welfare-improving provided that differences in initial programming $v_{0}$ are not too large.

16 Although in the Hotelling model, the market is 'covered' in that all consumers purchase at least a basic product, under exclusivity only a subset of consumers receive the premium content whereas under nonexclusivity all consumers receive premium content.

17 This finding may be sensitive to the modelling approach used in this subsection, in which it is straightforward for the integrated firm to extract consumer surplus using per-subscriber fees. With downward-sloping demand for premium content, consumers would retain some surplus and this finding might be qualified.
} 


$$
\Delta C S_{0}=-\frac{1}{36 t}(v+r)(18 t+v+r)<0
$$

\subsection{Discussion}

The clear-cut preference for non-exclusivity found in this Section, and further supported by the Bertrand model in Appendix A, is underpinned by two features of the model. The first is the scope for non-exclusive distribution to expand demand for the premium content, arising from product differentiation between the distributors. If the rival distributor merely diverted consumers from the integrated firm with no accompanying expansion in demand, then there would be little incentive to engage in wholesale supply. It should be noted that the terms of wholesale supply are endogenous: whatever contracting approach is used, it is reasonable to expect the terms of supply to adjust so that potential gains from trade are realised. Accordingly, the integrated operator can always find a wholesale contract which makes it more profitable to supply the rival distributor than to foreclose it. ${ }^{18}$ The Hotelling model in this Section facilitates efficient contracting but the result is not dependent on this structure: in the Bertrand model in Appendix A, contracting is not efficient (double marginalisation exists) yet the same non-exclusivity result is found.

The second feature supporting the non-exclusivity result is the per-subscriber wholesale fee. ${ }^{19}$ Commonly used in wholesale supply of television channels, ${ }^{20}$ a persubscriber fee has two implications. For the rival distributor, the per-subscriber fee represents a marginal cost of supplying an additional consumer. For the integrated operator, the fee creates an opportunity cost of winning subscribers from the rival distributor. The result is a softening of retail price competition, which allows the integrated firm to supply its rival and extract surplus from additional consumers while limiting retail competition that would otherwise undermine the value of its premium content. In the Hotelling framework of this Section, the per-subscriber fee is sufficient to achieve the efficient allocation: all consumers receive the premium content and transport costs are minimised. This result accords with the wider literature on contracting in the presence of externalities (see, inter alia, Segal, 1999): provided sufficient instruments are available, the seller chooses the efficient allocation.

The analysis in this Section might be seen as a basis for regulation to reduce wholesale channel fees: this would reduce retail prices for premium content,

\footnotetext{
18 As Madden and Pezzino comment on their foreclosure impossibility result: '[p]rovided the retailed goods are imperfect substitutes to some degree, the owner of the essential facility will always find a wholesale offer that provides enough wholesale revenue to compensate for any loss of retail market share' (Madden and Pezzino, 2013, p. 12).

${ }^{19}$ When wholesale contracting involves lump-sum payments only, Armstrong (1999) and Weeds (2014) show that exclusivity may instead arise. In Stennek (2014), the restriction to lump-sum payments similarly biases the analysis towards exclusivity.

${ }^{20}$ Per-subscriber fees are the norm in the wholesale supply of television channels. In practice, wholesale contracts may be more complex than the simple linear structure assumed here, incorporating minimum payments and/or discounts related to the proportion of the distributor's basic channel subscribers that are served: see Office of Fair Trading (2002) for a description of BSkyB's wholesale contracts.
} 
increasing benefits to consumers. However, such regulation may undermine wholesale supply: if the fee were regulated at too low a level, the integrated firm may prefer not to supply at all; then to overcome foreclosure, the regulation would need to be accompanied by an obligation to supply. It should also be noted that, by reducing the content provider's revenues, wholesale regulation might weaken incentives for investment in programme production and quality, potentially harming consumers.

Notice that the terms $v$ and $r$ often appear together in the profit expressions above. Advertising revenue $r$ is equivalent to a reduction in the seller's (net) marginal cost. There are strong similarities between a quality-raising input and a cost-reducing technology: it is unsurprising therefore that the terms appear together in this analysis. In the rest of the article, the somewhat redundant term $r$ is dropped.

The analysis of this Section, together with Appendix A, presents us with a puzzle: the findings suggest that premium content will always be distributed non-exclusively, yet in several instances exclusive distribution is observed. How can this be explained? While it is possible that wholesale supply negotiations may occasionally break down, exclusive distribution seems too prolonged and the pattern too consistent for this to be the primary explanation. Rather there would seem to be an additional factor not captured by the static analysis: potential future benefits from capturing retail market share from a competitor. The next Section examines the impact of dynamic aspects to competition on incentives for content distribution.

\section{Platform Competition with Switching Costs}

The model of Section 1 is now extended by adding a dynamic dimension to competition between distributors. This Section considers the impact of platform switching costs. The next Section outlines some alternative mechanisms, highlighting the general features that must be present for there to be a dynamic incentive for exclusivity.

When a consumer subscribes to pay TV, a set-up cost is incurred by the provider and/or consumer: this includes the purchase and installation of reception equipment, decoders, wiring, etc. If the consumer subsequently decides to switch to another provider, a further installation cost is incurred, as well as the time and inconvenience involved in switching. The cost is typically larger when the consumer switches to a different distribution technology (e.g. from cable to satellite) but there are also costs of switching between providers using similar technologies. Empirical estimates suggest that switching costs in pay TV are significant, equalling one-third to one-half of the annual bill (Shcherbakov, 2013).

Switching costs create a demand-side economy of scale between successive purchases from the same supplier. As a result consumers become 'sticky', tending to remain with the same provider even when the offer that initially attracted them has expired and the comparison with other distributors is no longer favourable. The extensive literature on switching costs, surveyed by Farrell and Klemperer (2007), teaches that in growing markets with many new consumers there is a strong incentive to compete fiercely to attract subscribers. Once consumers are locked in, however, switching costs can be exploited to extract additional consumer surplus. 
Switching costs are typically modelled using a two-period model. At the start of the first period, consumers are unattached and suppliers compete to sign them up; then, at the start of the second period, consumers are locked in and competition is softened by the presence of switching costs. In the following, the static framework of Section 1 is extended into a two-period model with switching costs to assess the incentive for content exclusivity in their presence.

\subsection{The Model with Switching Costs}

Competition takes place for two periods. In the first period, all consumers are new to the market, each subscribing to the distributor that offers the highest utility after transport costs. Distributors are unable to make binding commitments regarding future prices. In period 2, distributors compete again but consumers now face switching costs: ${ }^{21}$ a consumer that wishes to switch providers incurs a cost $\sigma \in[0, t){ }^{22}$ It is assumed that the distributors can price discriminate between their own and their rival's installed base of consumers. There may be an initial asymmetry between the distributors: the underlying quality of each distributor, distinct from premium content, is $v_{i 0}(i=A, B)$. Define $v_{\Delta} \equiv v_{A 0}-v_{B 0}$; it is assumed that $v_{\Delta} \geq 0$. The competitive market condition is

$$
t+\sigma \geq v_{\Delta}+v
$$

This condition, like (2) above, requires distributors to be sufficiently differentiated, given the attractiveness of premium content, that under exclusivity the distributor without premium content continues to supply some consumers. ${ }^{23}$

As before, distributor $A$ is vertically integrated with premium content (a channel, programme service or network) of quality $v$. At the start of each period, $A$ chooses whether or not to supply its premium content to rival distributor $B$. Contracting takes place as described in Section 1 above. Contracts last for a single period, thus an agreement for wholesale supply in period 1 does not guarantee that wholesale supply will be offered in period 2 (and, similarly, non-supply in period 1 does not preclude wholesale supply in period 2). Advertising revenue is ignored. For tractability it is assumed that there is no discounting of future profits. Details of the analysis are provided in Appendix B.

In period 2, $A$ always chooses to supply its premium content to the rival distributor (see Appendix B). The intuition follows from Section 1: with no further rounds the situation is static, thus non-exclusivity is chosen. Period 2 profits for $A$ and $B$ respectively are given by:

\footnotetext{
21 The incidence of switching costs is irrelevant: the same analysis would apply if distributors chose to subsidise this cost.

${ }^{22}$ The upper bound on $\sigma$ ensures that switching costs do not completely eliminate competition in period 2 (the consumer located at position 1 would potentially switch from $A$ to $B$ if both offered premium content at the same price). As noted in footnote 13, the condition is imposed for convenience so that interior solutions may be used but it could be relaxed.

23 Again, the condition is imposed to simplify the analysis by reducing the incidence of corner solutions, but could be relaxed.
} 


$$
\begin{aligned}
& \pi_{A}^{n e 2}=\frac{1}{18 t}\left(t+v_{\Delta}+\sigma+2 t s_{A}\right)^{2}+\frac{1}{18 t}\left(3 t+v_{\Delta}-\sigma-4 t s_{A}\right)^{2}+v \\
& \pi_{B}^{n e 2}=\frac{1}{18 t}\left(t+v_{\Delta}+\sigma-4 t s_{A}\right)^{2}+\frac{1}{18 t}\left(3 t-v_{\Delta}+\sigma-2 t s_{A}\right)^{2}
\end{aligned}
$$

where $s_{A}$ is $A$ 's period 1 market share. Combined industry profit in period $2\left(\pi_{A}^{n e 2}+\pi_{B}^{n e 2}\right)$ is convex in period 1 market share $s_{A}$, reaching its minimum at $s_{A}=\left[(1 / 2)+v_{\Delta}\right] /(10 t)$ and increasing as shares become more asymmetric.

Firm $A$ 's gain from exclusivity compared with non-exclusivity in period 1, given optimal period 2 behaviour, is given by the following expression (the derivation is provided in Appendix B)

$$
G_{\sigma}=\frac{v}{49 t}\left(18 v+20 v_{\Delta}-21 t\right) .
$$

Proposition 2 describes incentives for exclusivity in the presence of switching costs, showing that exclusivity is more likely for more valuable content and when distributors are less differentiated. Note also that if future profits were discounted, then the incentive for exclusivity would be increasing in the weight put on future profits, as there is profit sacrifice in period 1 in return for a gain in period 2.

Proposition 2 (Exclusivity with switching costs). The vertically integrated pay TV distributor with premium content chooses exclusivity in period 1 iff $t<(6 / 7) v+(20 / 21) v$. This condition implies that exclusivity is chosen under the following circumstances:

(a) For $v>\max \left\{\hat{v}_{\sigma}, 0\right\}$ where $\hat{v}_{\sigma} \equiv(7 / 6) t-(20 / 18) v_{\Delta}$. If $t \leq(20 / 21) v$, exclusivity is chosen for all $v$.

(b) For sufficiently small $t$.

Proof. $G_{\sigma}(v)>0$ requires $18 v+20 v_{\Delta}-21>0$. This is satisfied for $v>(7 / 6) t$ $-(20 / 18) v_{\Delta}$. If $t \leq(20 / 21) v_{\Delta}$ then the condition is always satisfied.

Proposition 2 is illustrated in Figure 1, which shows combinations of $t$ and $v$ generating each outcome.

The roles of the two parameters can be understood as follows.

- Little horizontal differentiation. With smaller $t$ consumers are easier to attract in competition with the rival distributor, raising the integrated firm's period 1 market share. This has two implications for its revenues, both of which encourage exclusivity. First, as demonstrated in Section 1, the opportunity cost of forgone wholesale fees under exclusivity in period 1 is reduced. Secondly, the higher period 1 market share confers a larger benefit in period 2 .

- Valuable content. There are two conflicting effects of higher $v$. As Section 1 shows, the opportunity cost of forgone wholesale fees under exclusivity is increasing in $v$. But, with larger $v$, the integrated firm's period 1 market share under exclusivity is higher, increasing its future benefit. For less valuable content, the first effect dominates and non-exclusivity is preferred but, for 


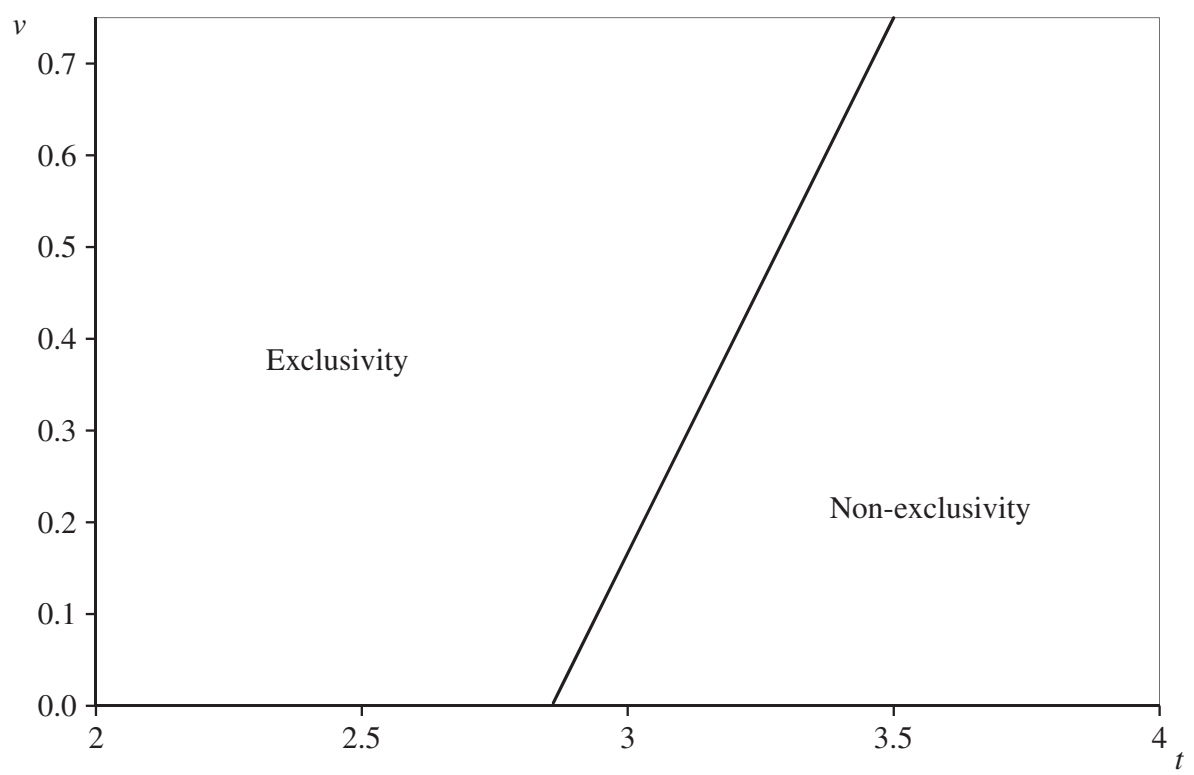

Fig. 1. Exclusivity with Switching Costs

Note. Parameter values used in the Figure are $\sigma=0.2$ and $v_{\Delta}=3$.

highly attractive content, the dynamic effect dominates and exclusivity is chosen.

With exclusivity consumers benefit from lower prices in period 1 but lose out from weaker competition in period 2, as is commonly found in models with switching costs. Comparing consumer surplus under non-exclusivity and exclusivity in period 1 (period 2 is always non-exclusive), taking account of switching costs incurred in period $2,{ }^{24}$ the difference is given by

$$
\Delta C S_{\sigma}=-\frac{v}{98 t}\left(49 t-18 v-27 v_{\Delta}\right)
$$

Thus exclusivity is the consumer optimum iff $t>\left(18 v+27 v_{\Delta}\right) / 49$. Consumers are more likely to prefer exclusivity for small $v$ and for large $t$, the opposite of the integrated firm's preference. by

Comparing total welfare under non-exclusivity and exclusivity, the difference is given

$$
\Delta W_{\sigma}=\frac{v}{98 t}\left(49 t-54 v-53 v_{\Delta}\right)
$$

Exclusivity is socially preferred iff $t<\left(54 v+53 v_{\Delta}\right) / 49$. Comparing this with the private optimum in Proposition 2, it can be seen that the social planner chooses exclusivity

24 Total switching costs incurred in period 2 are the same regardless of whether exclusivity or nonexclusivity is chosen in period 1 . 
more often than the integrated firm. This somewhat surprising result occurs for the following reason. Since firms can price discriminate between new and existing consumers, there is allocative inefficiency in period 2 - despite non-exclusive distribution - because each distributor supplies some consumers whose preference (at equal prices) is for their rival, incurring unnecessary transport costs. With greater asymmetry in period 1 market shares, more consumers purchase from their preferred distributor in period 2 and this inefficiency is reduced. This effect can outweigh the allocative efficiency losses in period 1, making exclusivity socially desirable. (However, this result may be sensitive to modelling choices, in particular the price discrimination assumption.)

\subsection{Discussion}

The finding that exclusivity may be chosen in the initial, 'sowing' phase of market development when consumers are unattached stems from the trade-off between the static net revenue gain from supplying the rival distributor (demonstrated in Section 1) and the future benefit from building market share. In the presence of switching costs, a higher market share today results in both a higher share and a higher price tomorrow, generating a convex relationship between current market share and future profit as observed following the profit expressions (5). A convex relationship is commonplace in the switching costs literature: for example, Beggs and Klemperer (1992) find that a firm's future value is quadratic in its current share. Convexity implies that the marginal benefit to building market share is increasing in the distributor's share. Thus, any initial advantage which generates asymmetric market shares is amplified: the larger distributor's incentive to build market shares become stronger while that of its rival weakens.

Exclusive content plays a crucial role in creating the initial asymmetry. Price competition alone cannot achieve this: when the distributors carry equally attractive content equilibrium market shares are equal. Note that in broadcasting, where the marginal cost of supplying an additional consumer is negligible, a competitive advantage cannot be achieved through cost-reducing innovation. Exclusive content is therefore the main instrument of dynamic competition. This analysis casts light on the importance of premium content in pay TV: this programming's particular attractiveness to viewers makes exclusivity an effective competitive strategy.

Rather than violating the principle in the contracting literature that, provided sufficient instruments are available, the content holder chooses the efficient allocation, the result is an instance of this. The holder implements the allocation which maximises industry profits but now in a dynamic rather than purely static setting. Although there is a loss of allocative efficiency, as some consumers with positive willingness to pay do not receive the premium content and transport costs are not minimised, the asymmetry generated by exclusive content nonetheless raises profits overall. If an alternative mechanism could be found to induce asymmetry, non-exclusive distribution would improve allocative efficiency in that all consumers would receive premium content (although transport costs would still be above the minimum). But price competition alone cannot generate asymmetry and a market-sharing agreement would fall foul of antitrust authorities - hence the unique role of exclusive premium content. 
This analysis demonstrates that, for a dynamic incentive for exclusivity to exist, two features must be present. There must be an intertemporal linkage between period 1 market share and period 2 profit; or, to put it more generally, a mechanism by which a higher market share has persistent effects. Secondly, there must be some form of scale effect such that greater asymmetry of market shares raises total industry profit, not just shifts profits from one firm to another. A switching cost creates both intertemporal linkage and a scale effect. The next Section briefly outlines two other mechanisms that may generate exclusivity: in each case the two necessary features of intertemporal linkage and a scale effect are present.

Switching costs have been analysed here using a two-period model in which all consumers are 'new' in period 1 and become 'old' in period 2. This framework could be extended in several ways. In a multi-period model exclusivity might be sustained for many periods, for as long as the future benefit from larger retail share exceeds the current benefit from wholesale supply: this could produce longer periods of exclusivity, as seen in pay TV in several countries. Alternatively, one could model a situation in which new consumers join the market every period and are served simultaneously with existing consumers: while distributors may be able to discriminate on price between the two groups, the integrated firm's choice of exclusivity (or not) would apply to both new and existing subscribers. This would raise the opportunity cost of exclusivity, as there would be forgone surplus from existing consumers as well as new ones, but exclusivity may nonetheless be chosen if the ratio of new to existing subscribers is sufficiently high.

In the model premium content is controlled by one of the distributors. This feature is convenient but not essential to the analysis. Similar outcomes might in principle be expected in the absence of vertical integration: ${ }^{25}$ given sufficient instruments specifically the ability to set appropriate per-subscriber wholesale fees - an independent content provider would choose the same allocation as the integrated firm. Commitment power would also be needed, either to guarantee exclusivity or to assure a distributor that its rivals will not receive preferential terms. ${ }^{26}$ There is one difference, however, between the integrated and non-integrated cases: with vertical integration the wholesale fee charged to the rival distributor determines the integrated firm's opportunity cost of winning subscribers from its competitor at the retail level, ${ }^{27}$ making wholesale supply an all-or-nothing decision. By contrast, an independent content provider could set different wholesale fees to different distributors, varying each one's incentive to compete for subscribers, allowing it to create precisely the desired degree of asymmetry via partial rather than full foreclosure. With vertical integration, this degree of control is not possible: interestingly, content supply is a blunter instrument under vertical integration than separation.

\footnotetext{
25 As Armstrong (1999) and Weeds (2014) show in settings with fixed fee payments, an independent content provider may choose to contract exclusively with one distributor.

${ }^{26}$ Such commitments are feasible in the television industry: exclusivity can be specified in wholesale contracts, and most favoured nation clauses or a common wholesale ratecard can be used to facilitate nondiscrimination.

27 The precise relationship between the wholesale fee and opportunity cost of winning subscribers follows from the mode of retail competition. In the Hotelling model, where diversion is one-for-one, the two are equal.
} 


\section{Other Dynamic Mechanisms}

This Section explores other possible dynamic mechanisms which may create an incentive for exclusive distribution of television content. In common with Section 2, these models display the two necessary features noted above: intertemporal linkage and a scale effect such that greater asymmetry increases industry profit.

\subsection{Platform Investment}

The attractiveness of a television service depends not only on the programming that is provided but also on the quality of the distribution platform. This may be improved through platform investment, for example, to expand distribution capacity or to facilitate high-definition and interactive services. Platform investment is typically a fixed cost - once this is incurred the improved service may be provided to many consumers at no additional cost - generating scale economies. Note that platform investment is investor-specific: unlike investment in programming, its benefit is not easily transferable to other distributors.

Platform investment is modelled as a dynamic game as follows. In the first stage the vertically integrated distributor $A$ chooses whether to supply its premium content $v$ to $B$, with contracting assumptions as before. In the second stage each distributor $i=A, B$ may invest in platform quality, $q_{i}$. In the third stage the distributors compete for consumers, choosing prices $p_{i}$, and consumers make subscription decisions. Consumer utility is given by $u_{i}=v_{i}+q_{i}-p_{i}$. Fixed costs depend on the level of quality chosen according to the convex function $\gamma q_{i}^{2} / 2$, where $\gamma>0$. The competitive market condition is ${ }^{28}$

$$
3 t \geq v+\frac{2}{3 \gamma} .
$$

This condition can be regarded as an extension of (2): note that it converges to that condition in the limit as $\gamma \rightarrow \infty$ and platform quality becomes fixed.

Detailed analysis is provided in Appendix C. Firm A's gain from exclusivity (compared with non-exclusivity) is given by

$$
G_{q}=\frac{\gamma(9 t \gamma-1)}{2(9 t \gamma-2)^{2}} v^{2}-\frac{(18 t \gamma-5)}{3(9 t \gamma-2)} v .
$$

Proposition 3 demonstrates that the integrated firm prefers exclusivity for more attractive content, less differentiated distributors and greater variability in platform quality.

Proposition 3 (Exclusivity with endogenous platform quality). The vertically integrated pay TV distributor with premium content chooses exclusivity under the following circumstances:

(a) For $v>\max \left\{\hat{v}_{q}, 0\right\} \quad$ where $\hat{v}_{q}=2(9 t \gamma-2)(18 t \gamma-5) /[3 \gamma(9 t \gamma-1)]$. If $18 t \gamma-5<0$ then exclusivity is chosen for all $v$.

\footnotetext{
${ }^{28}$ Concavity of profit functions requires $9 t \gamma-1>0$, while the competitive market condition further requires $9 t \gamma-2 \geq 3 v \gamma>0$. 
(b) For sufficiently small $t$.

(c) For sufficiently small $\gamma$.

Proof. The Proposition follows from the properties of $G_{q}(v)$.

(a) (i) If $(18 t \gamma-5) \leq 0, G_{q}(v)$ is positive for all $v>0$.

(ii) Otherwise, for $(18 t \gamma-5)>0, G_{q}(v)=0$ has two roots, 0 and $\hat{v}_{q}=(2 / 3 \gamma)[(9 t \gamma-2)(18 t \gamma-5) /(9 t \gamma-1)]>0$. For $v=0, \mathrm{~d} G_{q} / \mathrm{d} v<0$. $\mathrm{d}^{2} G_{q} / \mathrm{d} v^{2}=\gamma\left[(9 t \gamma-1) /(9 t \gamma-2)^{2}\right]>0$. Thus $G_{q}>0$ for $v>\hat{v}_{q}$.

(b) $\mathrm{d} G_{q} / \mathrm{d} \gamma<0$, and at $(18 t \gamma-5)=0, G_{q}>0$.

(c) $\mathrm{d} G_{q} / \mathrm{d} t<0$, and at $(18 t \gamma-5)=0, G_{q}>0$.

Proposition 3 reveals a third factor promoting exclusivity: the strength of the dynamic factor. When raising platform quality is less costly (i.e. $\gamma$ is lower) asymmetry in market shares has a greater impact on platform investment and the dynamic incentive for exclusivity is stronger.

Comparing consumer surplus under non-exclusivity and exclusivity, the difference is given by

$$
\Delta C S_{q}=-\frac{1}{2} v-\frac{9 t \gamma^{2}}{4(9 t \gamma-2)^{2}} v^{2}<0 .
$$

Hence consumers as a whole are better off under exclusivity, regardless of the cost of quality. However, while $A^{\prime}$ 's consumers always benefit $\left(u_{A}^{\text {excl }}>u_{A}^{n e}\right)$, depending on parameter values $B$ 's consumers may be better or worse off under exclusivity (i.e. it is possible that $\left.u_{B}^{e x c l}<u_{B}^{n e}\right)$. As well as having no access to premium content, $B$ 's consumers suffer from lower platform quality under exclusivity, though they pay a lower price.

Comparing total welfare under non-exclusivity and exclusivity, the difference is given by

$$
\Delta W_{q}=\frac{1}{2} v-\frac{\gamma(45 t \gamma-4)}{4(9 t \gamma-2)^{2}} v^{2} .
$$

Defining

$$
\bar{v}_{q} \equiv \frac{2(9 t \gamma-2)^{2}}{\gamma(45 t \gamma-4)},
$$

non-exclusivity (exclusivity) is socially preferred for $v<(>) \bar{v}_{q}$. The comparison of social and private thresholds, $\bar{v}_{q}$ and $\widehat{v}_{q}$, is ambiguous: the private operator may choose exclusivity too infrequently or too often compared with the social planner. As with the private optimum, the planner is more likely to choose exclusivity when distributors are less differentiated and quality is more variable.

\subsubsection{Discussion}

The desirability of exclusivity, for both the integrated distributor and the social planner, arises from economies of scale in platform investment. Fixed investment costs 
imply that quality can be provided more efficiently when consumers are served by the same distributor, with the result that industry profit is higher when market shares are asymmetric. Together with the persistence of platform investments - once investment is sunk at stage 2 it cannot be costlessly undone at stage 3 - the two features highlighted in Section 2 are present, generating a dynamic incentive for exclusivity.

\subsection{Exclusion}

In some circumstances a distributor may be able to exclude a rival by driving down the latter's profit, especially in the presence of significant fixed costs. In this setting content exclusivity may be used as an exclusionary strategy, as in the following simple extension of the static framework of Section 1.

At the start of period 1, integrated distributor $A$ chooses whether or not to supply its premium content $v$ to rival distributor $B$, with contracting assumptions as before. The firms then compete in prices. Suppose that if $B$ 's profit is reduced below a critical threshold $E$ for one period it then exits the market; the exit threshold depends on $B$ 's fixed costs, financial reserves, ability to raise outside finance, bankruptcy rules, merger control (if exit is via a distressed merger with $A$ ) etc. (This simple approach to exclusion ignores issues of commitment and credibility.) If $B$ exits, $A$ then becomes a monopolist in period 2, earning monopoly profit $\pi_{m}+v$ : this is assumed to exceed its static duopoly profit of $v+t / 2$. (Note that the supply of premium content is already monopolised: $A$ extracts its full value $v$ under both static duopoly and monopoly.) It is assumed that firms cannot commit to low prices but that $A$ can commit to its period 1 contracting choice.

If $E>t / 2$ then an exclusionary strategy is unnecessary: the static equilibrium with non-exclusive distribution is sufficient to induce exit. Suppose that $E<t / 2$. For exclusion to be effective requires

$$
\pi_{B}^{e x c l}=\frac{1}{18 t}(3 t-v)^{2}<E .
$$

Hence exclusivity is more effective as an exclusionary strategy for larger $v$ and smaller $t$, as these reduce the rival's profit. Larger $E$ implies that the target is weaker and hence easier to exclude.

For $A$ to have an incentive to exclude, its gain from monopoly in period 2 must exceed its opportunity cost from exclusivity in period 1. Its net gain is given by

$$
G_{E}=\pi_{m}-\frac{1}{18 t}\left(9 t^{2}+12 t v-v^{2}\right)
$$

This expression is increasing in $\pi_{m}$ and decreasing in both $v$ and $t$. With less valuable content the opportunity cost of forgone wholesale fees is lower, making exclusivity more attractive. Lower differentiation has two effects: $A$ has more to gain from monopolisation (the difference between $\pi_{m}$ and $t / 2$ is larger) and finds exclusion less costly (it can win customers over its rival more easily).

Putting these results together, exclusion through content exclusivity is both more effective and more desirable for the predator when firms are less 
differentiated. With highly attractive content the strategy is more effective but also more costly to the predator. While the model has assumed for simplicity that firms do not discount future profits, if discounting were incorporated the incentive for exclusivity would be increasing in the weight put on future profits because (as for other forms of predation) there is profit sacrifice in period 1 in return for a gain in period 2.

Regarding welfare, it is natural to assume that consumers are worse off under monopoly; moreover, even if they benefit from stronger price competition during the predatory period, subsequent monopolisation is likely to harm them overall. Thus, competition authorities are likely to regard exclusivity as detrimental when it forms part of an exclusionary strategy.

\subsubsection{Discussion}

In the case of exclusion, the incentive for exclusivity arises from its impact on industry structure: there is a scale effect arising from the loss of competition. The two necessary features noted above are present: inducing exit in period 1 has persistent effects since re-entry (or the entry of other firms) in period 2 is taken to be infeasible and, via monopolisation, asymmetry raises industry profit. This example also distinguishes the different roles played by $v$, the value of premium quality: the exclusion strategy is ineffective unless $v$ is large enough to satisfy expression (8) but thereafter larger $v$ increases its cost in terms of profit sacrifice in period 1 .

\section{Empirical and Policy Implications}

\subsection{Empirical Implications}

The analysis in this article explains the observed pattern of exclusivity in pay TV across many countries (bearing in mind that in some countries the ability to withhold programming is restricted by must-offer regulations). First, it explains why exclusivity is observed for premium channels while basic ones are widely distributed: as demonstrated by the comparative static in Proposition 2, exclusivity is chosen only for more highly valued programming.

Secondly, it explains why exclusivity tends to be observed in competition between relatively undifferentiated pay TV distributors, and why less differentiated rivals may be excluded while more differentiated distributors are supplied. To the extent that platform type is an important element of horizontal differentiation in the retail market, this explains the observation of exclusivity within a distribution technology (e.g. satellite-to-satellite) while distributors using other technologies (e.g. cable) are supplied. Prior to merger, satellite-based pay TV operators in France (CanalSat and TPS), Italy (Newscorp and Telepiù) and Spain (Sogecable and Vía Digital) competed with exclusive premium content; in Scandinavia, Canal Digital and Viasat continue to do so. However, in Italy Telepiù supplied its premium channels for distribution to Newscorp's cable (but not its satellite) subscribers; similarly in Scandinavia premium programming is supplied to competing cable, digital terrestrial (airwave) and IPTVbased distributors. 
While the dynamic features highlighted in Section 2 (switching costs) and subsection 3.1 (scale economies in platform investment) are commonly present in pay TV, particular circumstances are needed for dynamic effects to be sufficiently strong to generate exclusivity. As the two-period model in Section 2 highlights, building market share in the presence of switching costs is important when a large number of potential consumers are unattached. While in most countries the maturity of the pay TV industry implies that many consumers already subscribe to incumbent providers, there are times of transition when new consumers are drawn into the market and subscribers may make fresh decisions.

The emergence of a new distribution technology - such as IPTV, satellite or mobile TV - creates such a situation. The switching cost model can explain the use of exclusive premium content by European telecoms incumbents building IPTV platforms, ${ }^{29}$ US satellite operator DirecTV ${ }^{30}$ and emerging mobile TV services. Note, however, that since exclusivity is most desirable against rival distributors that: are less horizontally differentiated; and do not already have an installed subscriber base (as then the opportunity cost of non-supply is low), exclusive content offered by an IPTV operator (say) may best be seen as a competitive strategy between IPTV operators rather than against pay TV incumbents. This is reflected in the concern expressed by the French Authorité de la concurrence over the 'double exclusivity' business model employed by Orange/France Telecom, ${ }^{31}$ which tied access to its premium sports and movie content to a subscription to its 'triple play' service of telephony, broadband and TV, potentially distorting competition in the broadband market (Autorité de la concurrence, 2009).

The additional dynamic mechanisms described in Section 3 explain other situations in which exclusivity is observed. Scale economies in investment can explain the observation of exclusive content at times when the integrated operator and/or its rival (s) are building distribution platforms or investing in major enhancements (e.g. digitisation of their platforms). In the US, cable incumbents have exploited the 'terrestrial exemption' from wholesale supply regulations ${ }^{32}$ to deny regional sports

\footnotetext{
29 Belgium: Belgacom TV distributed live Jupiler Pro League football matches exclusively to its own broadband subscribers from 2005, until losing exclusive rights in 2011 (the author thanks Christian Huveneers of the Belgian Competition Authority for this information). France: Orange/France Télécom launched its premium Orange Sport and Orange Cinéma Séries channels in 2008 offering these exclusively to its own broadband subscribers. UK: in 2013 BT launched BT Sport, including 38 exclusive live FA Premier League football matches, offering this package to its own broadband subscribers at no additional charge while retailing it to BSkyB's satellite subscribers for a fee and wholesaling to cable operator Virgin Media.

${ }^{30}$ DirecTV entered with its exclusive NFL Sunday Ticket package, against satellite-based rival Dish Network and entrenched cable incumbents.

31 In 2008 Orange/France Telecom acquired exclusive live rights to French Ligue 1 matches and exclusive first pay TV window and library rights to movies and TV series from three US studios (Warner Bros, MGM and HBO), from which it created its premium Orange Sport and Orange Cinéma Séries channels. Once established in pay TV the operator changed its content distribution strategy: in 2011 it sold a stake in Orange Cinéma Séries to GCP, owner of the incumbent satellite distributor CanalSat - this service is now widely distributed - and in 2012 it closed Orange Sport.

32 Until 2010 the programme access rules, requiring vertically integrated operators to provide their programming to other distributors on non-discriminatory terms, did not apply to terrestrially-delivered content.
} 
programming to cable overbuilders, ${ }^{33}$ satellite entrants ${ }^{34}$ and new fibre-based video services. ${ }^{35}$ Here, content exclusivity operates as a strategy to hold back the rival's investment. Note that in these cases the opportunity cost of non-supply to a small entrant is low.

Occasionally exclusion of a rival is feasible. While cable's assets are largely sunk and unlikely to leave the market, satellite operators may be more susceptible to predation. Wars of attrition have taken place between satellite pay TV operators in several European countries (Spain, Italy, France) and between satellite-based pay-radio operators in the USA (Sirius and XM), in each case ending in a distressed merger. Content exclusivity has been a common feature of these wars of attrition, as each operator attempts to take retail share from its rival and drive the latter from the market.

When applying the article's analysis to real-world markets, one issue that arises is the interpretation of the market share condition in oligopoly markets with more than two distributors. In such instances, the condition that 'greater asymmetry in market shares raises industry profit' should be interpreted as follows: that raising the market share(s) of the integrated firm and any other distributor(s) it chooses to supply, and reducing those of the excluded distributors, increases industry profit. Note that in markets with more than two distributors, the profit-maximising choice may be to supply some rivals and exclude others, as observed in several pay TV markets.

\subsection{Messages For Policy}

The analysis in this article has a number of implications for policy. Although this discussion refers to pay TV, as noted in the Introduction the article's messages also apply to other sectors.

The first message is that for exclusion to occur in a setting where wholesale supply would expand demand there needs to be a coherent dynamic mechanism. Without such a mechanism the finding of the static framework in Section 1, supported by the Bertrand model in Appendix A and other literature, can be expected: an integrated distributor with premium content will always choose to supply rival distributors. This is not to say that every potential distributor that requests wholesale supply should necessarily be served: if doing so would not expand demand then supply would not be expected to take place. Moreover, the result is predicated on wholesale supply arrangements being commercially negotiated: if wholesale fees are regulated, perhaps in an attempt to reduce retail prices, the integrated operator might prefer not to supply.

\footnotetext{
33 For example, in Kansas City, Comcast and Time Warner used the terrestrial exemption to withhold college sports programming from Everest Connections Corp., a small cable entrant. Note that in the US, as elsewhere, cable overbuilding is rare, thus instances of cable-to-cable exclusivity are uncommon.

${ }^{34}$ For example, in Philadelphia, Comcast SportsNet is not available to satellite operators DirecTV and Dish Network.

${ }^{35}$ In San Diego, Cox Communications has withheld access to San Diego Padres games from AT\&T's U-Verse video service. In New York, Cablevision has barred U-Verse and Verizon's FiOS video service from carrying the high-definition format of its Madison Square Garden networks, which televise local sports matches.
} 
Secondly, the dynamic mechanism motivating exclusive distribution must be based on some form of scale effect such that greater asymmetry in market shares raises industry profit, combined with intertemporal linkage or persistence in effects. In pay $\mathrm{TV}$, scale economies and persistence typically arise from the characteristics of distribution platforms: platform investment incurs substantial fixed costs for suppliers and are largely sunk, while for consumers platform-specific reception equipment implies a switching cost of changing supplier, especially to one using a different distribution technology.

Other proposed dynamic mechanisms can be evaluated using the principles outlined here. In its 2007-10 Pay TV investigation, UK communications regulator Ofcom focused on a dynamic mechanism linking the acquisition of premium content rights to retail market shares. Ofcom alleged that BSkyB, as a large, vertically integrated distributor, had a strategic incentive to restrict wholesale supply of its premium sports and movie channels to rival distributors in order to prevent the latter from establishing a strong retail presence which would strengthen their positions when bidding against it for premium content rights (Ofcom, 2010, para. 7.197). Applying the analysis in this article, the two necessary features must be present for this mechanism to provide an incentive for exclusivity. First, there must be persistence in subscription decisions (e.g. due to switching costs) such that bidders' prior market shares affect their post-auction situations; otherwise, interested consumers would immediately switch to the latest winner of the content rights and pre-auction shares would be irrelevant. Secondly, content auctions must display a scale effect of the form described here: not only that larger distributors have an advantage over smaller ones but that greater retail market share confers increasing marginal benefit. Whether this condition is satisfied is not so obvious. The value of content rights to a bidder depends on the total audience it can reach, including via other distributors, not just its own subscribers. If greater surplus can be extract from one's own subscribers than from those of other distributors (e.g. due to vertical inefficiencies or contracting frictions) then a larger distributor may have a higher valuation of the rights than smaller ones (and independent programme producers), all else being equal, giving it a higher probability of winning the auction. However, for there to be an incentive for exclusivity there must be a convex - not merely linear - relationship between retail market share and profits. This question was not addressed in the investigation. ${ }^{36}$

The third message of the article is that welfare implications of exclusive content distribution are not straightforward. First, exclusivity is not necessarily harmful to consumers, notwithstanding the loss of allocative efficiency on the part of those consumers who do not receive the premium content and others who distort their choice of distributor in order to receive it. When content is widely distributed it is nonetheless monopolised - despite the appearance of competition - as per-subscriber fees support high consumer prices. By contrast, exclusivity generates stiffer price competition which may give greater benefit to consumers. Secondly, depending on the underlying dynamic mechanism, private and social incentives for exclusivity may be

\footnotetext{
36 A separate note (available from the author) finds that, in the context of an auction and wholesale contracting inefficiencies, the effect of distributor size on profit is linear, not convex, implying that this would not generate an incentive for exclusivity.
} 
aligned to a greater or lesser degree. If the dynamic incentive arises from economies of scale in investment or from consumer switching costs, exclusivity may benefit consumers as well as the integrated firm. However, the respective patterns of exclusivity may not match precisely: there may be instances where exclusivity is privately but not socially optimal or vice versa. An obvious divergence between private and social incentives arises when exclusivity is motivated by exclusion: while the integrated firm benefits from driving out its rival, one would expect consumers to be harmed by this. On the other hand, if exclusivity forms part of an entry strategy by a firm looking to grow its subscriber base consumers may benefit from this in the longer term. ${ }^{37}$ Furthermore, impacts on individual consumers may differ: while economies of scale in platform investment may imply that consumers in aggregate benefit from exclusivity, consumers with a strong intrinsic preference for the rival distributor's product are nonetheless harmed. Given all of this, it is crucial to understand the dynamic mechanism driving exclusivity and analyse its impacts explicitly, rather than to characterise exclusivity as harmful per se.

While this article has assumed that the premium content is controlled by one of the distributors, as noted in Section 2, similar outcomes might in principle be expected in the absence of vertical integration. If so, vertical separation does not guarantee wide distribution. In practice, however, vertical integration may play a role in facilitating exclusivity. In contracts between independent parties, the terms of supply must be fully specified and be enforceable. While full exclusivity might be relatively straightforward to implement with a commitment to withhold supply from all other distributors, a situation in which the content provider wishes to supply some distributors but not others (e.g. to supply a single operator on each distribution technology) would require the scope of exclusivity for each to be precisely defined. Furthermore, if dynamic benefits are realised over a lengthy period then to be effective the exclusive contract must have a long duration, but this may conflict with the parties' desire for flexibility, in case market conditions change over time, as well as inviting scrutiny from competition authorities.

In practice, regulation of channel supply has tended to focus on the distribution practices of integrated firms. In the US, the Programme Access Rules (PAR) historically prohibited vertically integrated distributors from withholding their content from other distributors. ${ }^{38}$ While the PAR may have prevented content exclusivity becoming the major issue it has been in many European countries, programming has occasionally been withheld from rival distributors (see instances noted in Section 1). Concerns over wholesale supply were raised in the Comcast/NBC Universal merger: this was cleared by the Federal Communications Commission in January 2011 subject to a condition (among others) to ensure that rival distributors continue to have access to ComcastNBCU programming.

\footnotetext{
37 In its assessment of the 'double exclusivity' model employed by Orange/France Telecom, the Autorité de la concurrence noted the potential benefit of entry into the pay TV market facilitated by the strategy, as well as its potential detriment to broadband competition (Autorité de la concurrence, 2009).

38 The PAR compelled vertically integrated distributors - which include the major cable operators - to offer satellite-delivered programming in which they have an ownership stake to other distributors on nondiscriminatory terms. The PAR expired in October 2012, being replaced with a case-by-case approach.
} 
In the model presented here, premium content is a unique collection of highly attractive programming controlled by the integrated firm. Exclusivity is a powerful competitive strategy when consumers attach high values to a particular type of programming (e.g. live sports, first-run movies) and, within this, on a limited number of outputs (e.g. football/soccer matches played by the national league, blockbuster movies produced by Hollywood studios). Production of such programming often requires televisation rights to be acquired from providers further upstream (sports teams or leagues, movie studios). When there is a limited range of important content this is relatively easy to monopolise: a sports league selling its rights collectively naturally prefers to contract with a single buyer as this maximises their value, and even when potentially competing rights are available - as from the Hollywood majors - these are often acquired by a single operator (e.g. BSkyB in the UK).

Competition authorities have attempted to intervene further upstream to restrict the monopolisation of premium content by a single pay TV operator, as a means of overcoming the potential harmful effects highlighted in this article (which, understood fully, include wide distribution at high retail prices as well as the possible foreclosure of rival distributors). In Europe, several national football leagues have been compelled to split their televisation rights into a number of packages, sometimes (as in the case of the FA Premier League) combined with a no-single-buyer rule ensuring that more than one pay TV operator acquires premium rights. However, these attempts have had little success in reducing retail prices or preventing disputes over exclusive distribution of programming; indeed, avid football fans have criticised such measures for increasing the total price they must pay to watch all matches. Where certain premium content confers a strong position and is difficult to break up, the distribution of programming remains an area of concern to policy makers.

\section{Conclusion}

This article examines incentives for exclusive distribution of programme content in pay TV. In settings where wholesale supply would be expected to expand demand, exclusivity cannot be explained in a purely static setting: there must also be a dynamic benefit from building market share, resulting from some form of scale effect such that industry profits are increasing in the asymmetry of market shares. In accordance with the contracting literature, the content holder chooses the allocation that maximises industry profit, which, under certain conditions, implies exclusivity. The analysis explains the observed incidence of exclusive content in pay TV and provides guidance to policy makers in assessing the scope for, and effects of, content exclusivity.

The importance of exclusive content in pay TV arises in part from the industry's cost function, which has a large first-copy cost for programming and significant set-up costs for distribution systems, after which consumers may be served at minimal incremental cost. While firms in other industries may compete by reducing their marginal costs, this is not possible in pay TV as marginal cost is already negligible. Since neither cost reductions nor price competition (which on its own cannot generate asymmetry) can play this role, content exclusivity is the primary means by which distributors can compete for market share. With economies of scale at the platform level, content exclusivity may become an attractive strategy. 
While this article focuses on pay TV, its relevance extends to many other sectors. The growth of internet-based and mobile distribution services for music and video may lead to content exclusively being increasingly used as a competitive strategy online and on mobile platforms, as it has been in pay TV: the analysis is relevant for these forms of distribution too. Beyond this, content exclusivity is an important competitive strategy in any industry where attractive content drives consumer choice. The analysis can equally be applied to 'killer apps' for computer platforms, for example, the Lotus 1-2-3 spreadsheet software for IBM's PC in the mid-1980s and, more recently, application software that is specific to a particular mobile phone operating system. It also applies to popular video games, which are typically exclusive to a particular gaming console, for example, Space Invaders for the Atari VCS, Sonic the Hedgehog for the Sega Mega Drive and Super Mario for the Nintendo 64. More generally, input foreclosure may occur in any sector where a crucial input required for downstream competition is controlled by one player, for example, the local loop for broadband competition. The article's analysis casts light on all of these situations.

\section{Appendix A. Bertrand Model}

This Appendix sets out an alternative model for the static analysis in Section 1. The model presented here, based on Bertrand duopoly in differentiated goods, relaxes the restrictive features of the Hotelling-based framework: with downward-sloping demand there is incomplete coverage and, given linear wholesale fees, vertical contracting is inefficient in that double marginalisation is present. ${ }^{39}$ This implies that the integrated firm typically fails to extract all surplus both from consumers and from the rival distributor (under non-exclusive distribution). Nonetheless, the analysis in this Appendix demonstrates that the static finding that the integrated operator always chooses to supply the rival distributor holds even under these conditions.

Two distributors, $i=A, B$, supply television programming to consumers (viewers). They compete in prices, adjusted for quality, and their products are horizontally differentiated. Demand facing distributor $i$ is given by

$$
q_{i}=\alpha-\beta\left(p_{i}-v_{i}\right)+\gamma\left(p_{j}-v_{j}\right),
$$

where $\alpha, \beta, \gamma>0, \beta>\gamma$ and $v_{i}$ denotes the quality of programming supplied by $i$. The quality of basic programming (and any bundled retail services) is normalised at 0 . $A$ is vertically integrated with a premium content (a television channel, programme service or network) of quality $v$ which it supplies to its own retail customers, thus $v_{A}=v$. If $A$ supplies its premium content to $B$ then $v_{B}=v$; otherwise $v_{B}=0$. The assumption $\beta>\gamma$ implies that the demand-expansion effect of wholesaling the premium content to the rival distributor exceeds the diversion of demand from the integrated operator. If wholesale supply takes place, $A$ charges $B$ a wholesale fee per subscriber denoted $w$. Other than this fee, the marginal cost of supplying a consumer is zero. Advertising is ignored.

The structure of the game is as follows. In the first period, $A$ decides whether to offer its premium content to $B$, specifying if it does so a per-subscriber wholesale fee $w$. If offered a

\footnotetext{
39 Alternatively, one could assume that contracting is efficient and producer surplus is divided between the parties according to the Nash bargaining solution. This approach increases the profits of the contracting firms and hence is more favourable towards non-exclusivity. By incorporating contracting inefficiency (due to linear wholesale fees) the approach used in this Appendix is less favourable towards non-exclusivity, thus strengthening the findings.
} 
contract $B$ then accepts or rejects this. If a wholesale contract is both offered and accepted, $B$ supplies the premium content to its consumers; otherwise $B$ supplies basic programming only. In the second stage, the distributors compete in prices. The following parameter restriction is required to ensure that prices remain positive and is assumed throughout

$$
v \leq v_{\max } \equiv \frac{\alpha}{\beta \gamma}(2 \beta+\gamma)
$$

In the following analysis, outcomes are derived for exclusive and non-exclusive supply; these are then compared to assess $A$ 's incentive towards exclusivity.

When $A$ supplies its premium programming exclusively to its own consumers, distributor $i$ 's profit is given by $\pi_{i}=p_{i} q_{i}$. Profits under exclusivity are:

$$
\begin{gathered}
\pi_{A}^{e x c l}=\frac{\beta}{(2 \beta+\gamma)^{2}(2 \beta-\gamma)^{2}}\left[\alpha(2 \beta+\gamma)+v\left(2 \beta^{2}-\gamma^{2}\right)\right]^{2} ; \\
\pi_{B}^{e x c l}=\frac{\beta}{(2 \beta+\gamma)^{2}(2 \beta-\gamma)^{2}}[\alpha(2 \beta+\gamma)-v \beta \gamma]^{2} .
\end{gathered}
$$

Condition (A.2) ensures that $\pi_{B}>0$. Notice that $\pi_{A}>\pi_{B}$ with this difference increasing in $v$.

When $A$ supplies its premium content to $B$, profits are given by:

$$
\begin{aligned}
& \pi_{A}^{n o n}=p_{A} q_{A}+w q_{B} ; \\
& \pi_{B}^{n o n}=\left(p_{B}-w\right) q_{B} .
\end{aligned}
$$

$A$ chooses wholesale fee $w$ to maximise its profit. However there is a range of parameter values over which $A$ 's (notionally) profit-maximising choice of $w$ would be rejected by $B$, as $B$ makes a higher profit under exclusivity. For the contract to be accepted over this interval $A$ must offer a lower wholesale fee that satisfies $B$ 's participation constraint $\pi_{B}^{n o n} \geq \pi_{B}^{e x c l}$. Taking this into account $A$ 's profit-maximising choice of wholesale fee is

$$
w= \begin{cases}\widehat{w}=\frac{\left(2 \beta^{2}-\gamma^{2}\right)}{2(\beta+\gamma)(\beta-\gamma)} v & \text { for } v \in\left(0, \widehat{v}_{1}\right] \\ w^{*}=\frac{(2 \beta+\gamma)\left(4 \beta^{2}-2 \beta \gamma+\gamma^{2}\right)}{2 \beta(\beta-\gamma)\left(8 \beta^{2}+\gamma^{2}\right)}[\alpha+v(\beta-\gamma)] & \text { for } v \in\left[\widehat{v}_{1}, v_{\max }\right]\end{cases}
$$

where $^{40}$

$$
\widehat{v}_{1}=\frac{\left(4 \beta^{2}-2 \beta \gamma+\gamma^{2}\right)(\beta+\gamma)(2 \beta+\gamma)}{\left(8 \beta^{5}+\gamma^{5}-\beta \gamma^{4}-\beta^{2} \gamma^{3}+2 \beta^{3} \gamma^{2}\right)} \alpha .
$$

It can be shown that $\widehat{w}<w^{*}$ for $v \in\left(0, \widehat{v}_{1}\right)$, as expected. Notice that the wholesale fee is increasing in $v$. In the unconstrained case (i.e. for $v \in\left[\widehat{v}_{1}, v_{\max }\right]$, with wholesale fee given by $w^{*}$ ) profits under non-exclusivity are

$$
\pi_{A}^{n o n}=\frac{(2 \beta+\gamma)\left(6 \beta^{2}-\beta \gamma+\gamma^{2}\right)}{4 \beta(\beta-\gamma)\left(8 \beta^{2}+\gamma^{2}\right)}[\alpha+v(\beta-\gamma)]^{2} ;
$$

${ }^{40} \pi_{B}^{n o n}=\pi_{B_{5}}^{e x c l}$ has another root, $\widehat{v}_{2}=-\alpha(2 \beta+\gamma)\left(12 \beta^{3}-2 \beta^{2} \gamma+3 \beta \gamma^{2}-\gamma^{3}\right) /\left(8 \beta^{5}-16 \beta^{4} \gamma+2 \beta^{3} \gamma^{2}-\right.$ $\left.3 \beta^{2} \gamma^{3}-\beta \gamma^{4}+\gamma^{5}\right)$. Depending on parameter values either $\widehat{v}_{2}<0$ or $\widehat{v}_{2}>v_{\max }$, hence this second root is not relevant.

(C) 2014 The Authors.

The Economic Journal published by John Wiley \& Sons Ltd on behalf of Royal Economic Society. 


$$
\pi_{B}^{n o n}=\frac{\left(2 \beta^{2}+\gamma^{2}\right)^{2}}{\beta\left(8 \beta^{2}+\gamma^{2}\right)^{2}}[\alpha+v(\beta-\gamma)]^{2} .
$$

When $B$ 's participation constraint binds (i.e. for $v \in\left(0, \widehat{v}_{1}\right]$, with wholesale fee given by $\left.\widehat{w}\right)$ profits under non-exclusivity are given by:

$$
\begin{aligned}
& \widehat{\pi}_{A}^{n o n}= \frac{\beta}{(2 \beta-\gamma)^{2}} \alpha^{2}+\frac{16 \beta^{4}-16 \beta^{3} \gamma-2 \beta^{2} \gamma^{2}+6 \beta \gamma^{3}-\gamma^{4}}{2(\beta-\gamma)(2 \beta-\gamma)^{2}(2 \beta+\gamma)} \alpha \nu \\
&+ \frac{16 \beta^{6}(\beta-\gamma)-48 \beta^{5} \gamma^{2}+28 \beta^{3} \gamma^{3}(\beta+\gamma)-14 \beta^{2} \gamma^{5}-5 \beta \gamma^{6}+2 \gamma^{7}}{4(\beta+\gamma)(\beta-\gamma)(2 \beta-\gamma)^{2}(2 \beta+\gamma)^{2}} v^{2} ; \\
& \widehat{\pi}_{B}^{\text {non }}=\frac{\beta}{(2 \beta+\gamma)^{2}(2 \beta-\gamma)^{2}}[\alpha(2 \beta+\gamma)-v \beta \gamma]^{2}=\pi_{B}^{e x c l} .
\end{aligned}
$$

To assess A's incentives for exclusivity we assess the sign of its gain from exclusivity, $G=\pi_{A}^{e x c l}-\pi_{A}^{n o n}$. In the unconstrained case in which $A$ 's choice of wholesale fee is $w^{*}$ this is given by

$$
G=-M_{0} \alpha^{2}-M_{1} \alpha v-M_{2} v^{2}
$$

where

$$
\begin{aligned}
& M_{0}=\frac{(\beta+\gamma)\left(4 \beta^{2}-2 \beta \gamma+\gamma^{2}\right)^{2}}{4 \beta(\beta-\gamma)\left(8 \beta^{2}+\gamma^{2}\right)(2 \beta-\gamma)^{2}}>0 \\
& M_{1}=\frac{32 \beta^{6}-16 \beta^{5} \gamma-8 \beta^{4} \gamma^{2}+8 \beta^{3} \gamma^{3}+2 \beta^{2} \gamma^{4}-\beta \gamma^{5}+\gamma^{6}}{2 \beta\left(8 \beta^{2}+\gamma^{2}\right)(2 \beta+\gamma)(2 \beta-\gamma)^{2}}>0 \\
& M_{2}=\frac{64 \beta^{8}-128 \beta^{7} \gamma-32 \beta^{6} \gamma^{2}+64 \beta^{5} \gamma^{3}+4 \beta^{4} \gamma^{4}-8 \beta^{3} \gamma^{5}+\beta^{2} \gamma^{6}-\gamma^{8}}{4 \beta\left(8 \beta^{2}+\gamma^{2}\right)(2 \beta+\gamma)^{2}(2 \beta-\gamma)^{2}} .
\end{aligned}
$$

If the three coefficients $M_{0}, M_{1}$ and $M_{2}$ are positive then clearly $G<0$. While $M_{0}, M_{1}>0$, it is possible that $M_{2}<0$ : in this case $G$ is convex and becomes positive for sufficiently large $v$. Evaluating $G$ at the upper bound $v_{\max }$ it can be shown that $G\left(v_{\max }\right)<0$, thus $G<0$ for $v \in\left[\widehat{v}_{1}, v_{\max }\right]$.

When B's participation constraint binds and A's choice of wholesale fee is $\widehat{w}$, we have

$$
\widehat{G}=-\frac{\left(2 \beta^{2}-2 \beta \gamma+\gamma^{2}\right)}{2(\beta-\gamma)(2 \beta-\gamma)} \alpha \nu+\frac{\gamma\left(4 \beta^{4}+4 \beta^{3} \gamma-6 \beta^{2} \gamma^{2}-\beta \gamma^{3}+2 \gamma^{4}\right)}{4(\beta+\gamma)(\beta-\gamma)(2 \beta+\gamma)(2 \beta-\gamma)} v^{2} .
$$

Clearly, $\widehat{G}(0)=0$. Since the second term is positive, $\widehat{G}$ is convex, becoming positive for sufficiently large $v$. Evaluating $\widehat{G}$ at the boundary $\widehat{v}_{1}$ it can be shown that $\widehat{G}\left(\widehat{v}_{1}\right)<0$, thus $\widehat{G}<0$ for $v \in\left(0, \widehat{v}_{1}\right]$. Since $G<0$ and $\widehat{G}<0$ over the relevant intervals, $A$ always chooses non-exclusivity.

The two firms' profits under exclusivity and non-exclusivity respectively, as functions of content value $v$, are illustrated by the numerical simulation shown in Figure A1. The Figure shows profits of the two firms for values of $v$ between 0 and $v_{\max }=5$. With these parameter values $\widehat{v}_{1} \simeq 1.46$.

(C) 2014 The Authors.

The Economic Journal published by John Wiley \& Sons Ltd on behalf of Royal Economic Society. 
Profits

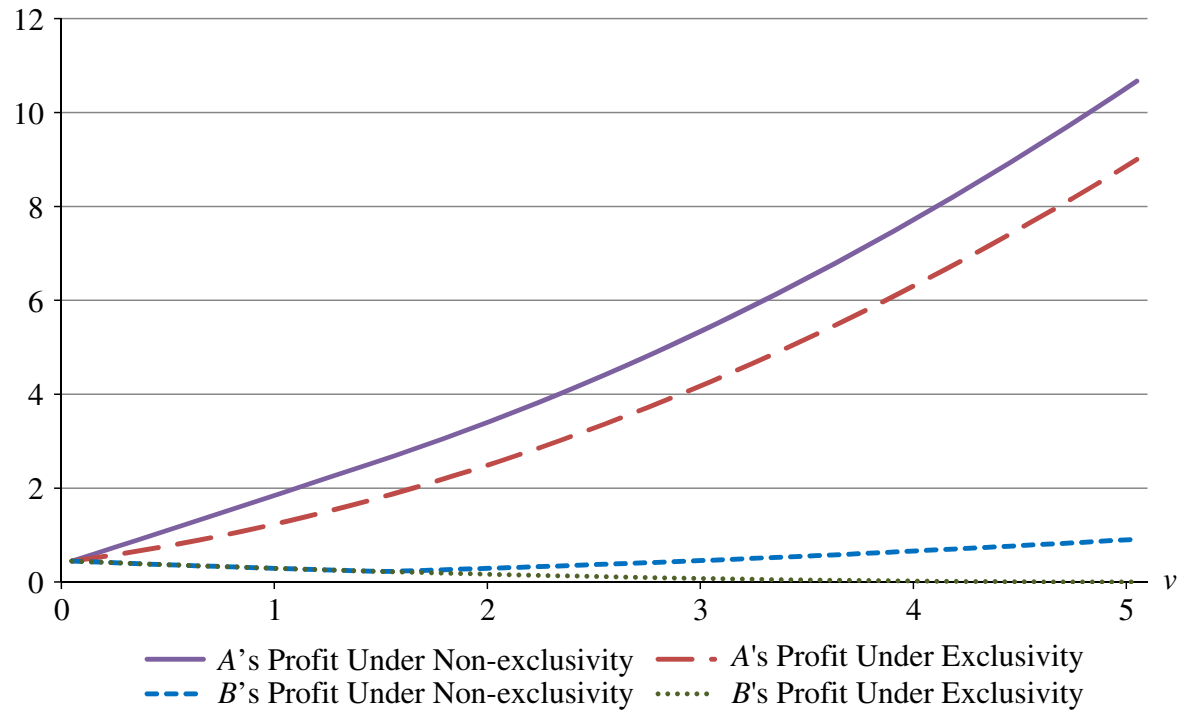

Fig. A1. Bertrand Model Profits

Note. Parameter values used in the Figure are $\alpha=\beta=1$ and $\gamma=1 / 2$.

\section{Appendix B. Switching Costs}

The model is solved backwards

\section{B.1. Period 2: Competition with Installed Subscriber Bases}

$A$ 's period 1 market share is denoted $s_{A}$. Distributors can discriminate between their own and the rival's installed base, generating two sub-markets in period 2. The analysis allows for the possibility that one of the two sub-markets may be monopolised in period 2 (i.e. A's installed base is served by $A$ alone, or $B$ 's installed base is served by $B$ alone). The following condition ensures that at least one of the sub-markets remains competitive (and hence that $B$ is not driven out of the market) under exclusivity and non-exclusivity

$$
t+\sigma \geq v_{\Delta}+v
$$

Denoting by $p_{j i}$ the price offered by $i$ to $j$ 's installed base, indifferent consumers in the two submarkets are located at $x \in\left[0, s_{A}\right]$ and $y \in\left[s_{A}, 1\right]$ where:

$$
\begin{aligned}
& x=\frac{1}{2 t}\left(t+v_{A}-v_{B}+\sigma-p_{A A}+p_{A B}\right) ; \\
& y=\frac{1}{2 t}\left(t+v_{A}-v_{B}-\sigma-p_{B A}+p_{B B}\right) .
\end{aligned}
$$

Under exclusivity, $v_{A}-v_{B}=v_{\Delta}+v$; solving for period 2 equilibrium, profits as functions of $s_{A}$ are given by 


$$
\begin{aligned}
& \text { for } s_{A}<\frac{1}{4 t}\left(t+v+v_{\Delta}+\sigma\right) \text { : } \\
& \qquad \begin{aligned}
\pi_{A}^{e x 2} & =s_{A}\left(t+v+v_{\Delta}+\sigma-2 t s_{A}\right)+\frac{1}{18 t}\left(3 t+v+v_{\Delta}-\sigma-4 t s_{A}\right)^{2} \\
\pi_{B}^{e x 2} & =\frac{1}{18 t}\left(3 t-v-v_{\Delta}+\sigma-2 t s_{A}\right)^{2} \\
\text { for } s_{A} & \in\left[\frac{1}{4 t}\left(t+v+v_{\Delta}+\sigma\right), \frac{1}{4 t}\left(3 t+v+v_{\Delta}-\sigma\right)\right]: \\
\pi_{A}^{e x 2} & =\frac{1}{18 t}\left(t+v+v_{\Delta}+\sigma+2 t s_{A}\right)^{2}+\frac{1}{18 t}\left(3 t+v+v_{\Delta}-\sigma-4 t s_{A}\right)^{2} \\
\pi_{B}^{e x 2} & =\frac{1}{18 t}\left(t+v+v_{\Delta}+\sigma-4 t s_{A}\right)^{2}+\frac{1}{18 t}\left(3 t-v-v_{\Delta}+\sigma-2 t s_{A}\right)^{2} \\
\text { for } s_{A}> & \frac{1}{4 t}\left(3 t+v+v_{\Delta}-\sigma\right): \\
\pi_{A}^{e x 2} & =\frac{1}{18 t}\left(t+v+v_{\Delta}+\sigma+2 t s_{A}\right)^{2} ; \\
\pi_{B}^{e x 2} & =\frac{1}{18 t}\left(t+v+v_{\Delta}+\sigma-4 t s_{A}\right)^{2}+\left(1-s_{A}\right)\left(2 t s_{A}-t-v-v_{\Delta}+\sigma\right) .
\end{aligned}
\end{aligned}
$$

Under non-exclusive distribution, $v_{A}-v_{B}=v_{\Delta}$; solving for period 2 equilibrium, profits as functions of $s_{A}$ are

$$
\begin{aligned}
& \text { for } s_{A}<\frac{1}{4 t}\left(t+v_{\Delta}+\sigma\right) \text { : } \\
& \pi_{A}^{n e 2}=s_{A}\left(t+v+v_{\Delta}+\sigma-2 t s_{A}\right)+\frac{v}{6 t}\left(3 t-v_{\Delta}+\sigma-2 t s_{A}\right) \\
& +\frac{1}{18 t}\left(3 t+v_{\Delta}-\sigma-4 t s_{A}\right)\left(3 t+3 v+v_{\Delta}-\sigma-4 t s_{A}\right) \\
& \pi_{B}^{n e 2}=\frac{1}{18 t}\left(3 t-v_{\Delta}+\sigma-2 t s_{A}\right)^{2} \\
& \text { for } s_{A} \in\left[\frac{1}{4 t}\left(t+v_{\Delta}+\sigma\right), \frac{1}{4 t}\left(3 t+v_{\Delta}-\sigma\right)\right] \text { : } \\
& \pi_{A}^{n e 2}=\frac{1}{18 t}\left(t+v_{\Delta}+\sigma+2 t s_{A}\right)^{2}+\frac{1}{18 t}\left(3 t+v_{\Delta}-\sigma-4 t s_{A}\right)^{2}+v \\
& \pi_{B}^{n e 2}=\frac{1}{18 t}\left(t+v_{\Delta}+\sigma-4 t s_{A}\right)^{2}+\frac{1}{18 t}\left(3 t-v_{\Delta}+\sigma-2 t s_{A}\right)^{2} \\
& \text { for } s_{A}>\frac{1}{4 t}\left(3 t+v_{\Delta}-\sigma\right) \text { : } \\
& \pi_{A}^{n e 2}=\frac{1}{18 t}\left(t+v_{\Delta}+\sigma+2 t s_{A}\right)\left(t+3 v+v_{\Delta}+\sigma+2 t s_{A}\right)+\frac{v}{6 t}\left(5 t-v_{\Delta}-\sigma-2 t s_{A}\right) ; \\
& \pi_{B}^{n e 2}=\frac{1}{18 t}\left(t+v_{\Delta}+\sigma-4 t s_{A}\right)^{2}+\frac{1}{2}\left(t+\sigma-v_{\Delta}\right)\left(1-s_{A}\right) .
\end{aligned}
$$


Comparing the relevant profit expressions over each interval of $s_{A}$ it can be shown that $A$ 's gain from exclusivity in period 2 is always negative; ${ }^{41}$ i.e. non-exclusive distribution is always chosen in period 2. This is not surprising: the situation in period 2 is equivalent to the static model of Section 1. Focusing on the intermediate case where both sub-markets are competitive, note that period 2 profits are convex in period 1 share $s_{A}$ : combined industry profit is at a minimum at $\left.s_{A}=\left[(1 / 2)+v_{\Delta}\right] / 10 t\right)$, and increases as shares become more asymmetric.

\section{B.2. Period 1: Competition for New Subscribers}

At the start of period 1 no consumer is locked in and each retailer sets a single price $\left(p_{i} ; i=A, B\right)$. However, they now take account of the impact of their period 1 decisions on period 2 outcomes. To simplify the analysis I shall focus on the case where both period 2 sub-markets remain competitive, $s_{A} \in\left[\left(t+v_{\Delta}+\sigma\right) /(4 t),\left(3 t+v_{\Delta}-\sigma\right) /(4 t)\right]$; this requires the following parameter restriction to hold:

$$
t>\sigma+\frac{18}{7} v+\frac{3}{7} v_{\Delta}
$$

Suppose that $A$ chooses exclusivity in period 1 . In this case $A$ 's period 1 market share is $s_{A}^{\text {excl }}=\left(t-p_{A}+p_{B}+v_{\Delta}+v\right) /(2 t)$ and the firms' total profits over the two periods can be expressed as

$$
\begin{aligned}
& \pi_{A}^{e x c l}=p_{A} s_{A}^{e x c l}+\frac{1}{18 t}\left(t+v_{\Delta}+\sigma+2 t s_{A}^{e x c l}\right)^{2}+\frac{1}{18 t}\left(3 t+v_{\Delta}-\sigma-4 t s_{A}^{e x c l}\right)^{2}+v \\
& \pi_{B}^{e x c l}=p_{B}\left(1-s_{A}^{e x c l}\right)+\frac{1}{18 t}\left(t+v_{\Delta}+\sigma-4 t s_{A}^{e x c l}\right)^{2}+\frac{1}{18 t}\left(3 t-v_{\Delta}+\sigma-2 t s_{A}^{e x c l}\right)^{2} .
\end{aligned}
$$

Solving for equilibrium under exclusivity one can derive $p_{A}^{\text {excl }}=t-2 \sigma / 3+\left(v_{\Delta}-v\right) / 7$, $p_{B}^{\text {excl }}=t-2 \sigma / 3-\left(v_{\Delta}-v\right) / 7$ and $s_{A}^{\text {excl }}=(1 / 2)+\left(5 v_{\Delta}+9 v\right) /(14 t)$; thus

$$
\begin{aligned}
& \pi_{A}^{e x c l}=\frac{7}{9} t-\frac{2}{9} \sigma+\frac{1}{9 t} \sigma^{2}+\frac{1}{49 t}\left(20 v v_{\Delta}+18 v^{2}+11 v_{\Delta}^{2}\right)+\frac{16}{21} v_{\Delta}+\frac{11}{7} v \\
& \pi_{B}^{e x c l}=\frac{7}{9} t-\frac{2}{9} \sigma+\frac{1}{9 t} \sigma^{2}+\frac{1}{49 t}\left(20 v v_{\Delta}+18 v^{2}+11 v_{\Delta}^{2}\right)-\frac{16}{21} v_{\Delta}-\frac{4}{7} v
\end{aligned}
$$

Suppose instead that $A$ chooses non-exclusivity in period 1 . In this case $A$ 's period 1 market share is $s_{A}^{n e}=\left(t-p_{A}+p_{B}+v_{\Delta}\right) /(2 t)$ and the firms' total profits over the two periods can be expressed as:

$$
\begin{aligned}
& \pi_{A}^{n e}=p_{A} s_{A}^{n e}+v\left(1-s_{A}^{n e}\right)+\frac{1}{18 t}\left(t+v_{\Delta}+\sigma+2 t s_{A}^{n e}\right)^{2}+\frac{1}{18 t}\left(3 t+v_{\Delta}-\sigma-4 t s_{A}^{n e}\right)^{2}+v \\
& \pi_{B}^{n e}=\left(p_{B}-v\right)\left(1-s_{A}^{n e}\right)+\frac{1}{18 t}\left(t+v_{\Delta}+\sigma-4 t s_{A}^{n e}\right)^{2}+\frac{1}{18 t}\left(3 t-v_{\Delta}+\sigma-2 t s_{A}^{n e}\right)^{2} .
\end{aligned}
$$

Solving for equilibrium under non-exclusivity one can derive $p_{A}^{n e}=t-2 \sigma / 3+v+3 v_{\Delta} / 21$, $p_{B}^{n e}=t-2 \sigma / 3+v-3 v_{\Delta} / 21$ and $s_{A}=\left[(1 / 2)+5 v_{\Delta}\right] /(14 t) ;$ thus:

${ }^{41}$ In each case $G_{\sigma}^{(2)}=\pi_{A}^{e x 2}-\pi_{A}^{n e 2}$ is convex in $s_{A}$, decreasing at first and then increasing. The expression can be shown to be negative at both end-points of the relevant interval of $s_{A}$, thus it is negative throughout the interval.

(C) 2014 The Authors.

The Economic Journal published by John Wiley \& Sons Ltd on behalf of Royal Economic Society. 


$$
\begin{aligned}
\pi_{A}^{n e} & =\frac{7}{9} t-\frac{2}{9} \sigma+\frac{1}{9 t} \sigma^{2}+\frac{11}{49 t} v_{\Delta}^{2}+\frac{16}{21} v_{\Delta}+2 v \\
\pi_{B}^{n e} & =\frac{7}{9} t-\frac{2}{9} \sigma+\frac{1}{9 t} \sigma^{2}+\frac{11}{49 t} v_{\Delta}^{2}-\frac{16}{21} v_{\Delta} .
\end{aligned}
$$

Calculating A's gain from exclusivity in period 1 given period 2 equilibrium, $G_{\sigma}=\pi_{A}^{e x c l}-\pi_{A}^{n e}$, one can derive

$$
G_{\sigma}=\frac{v}{49 t}\left(18 v+20 v_{\Delta}-21 t\right)
$$

\section{Appendix C. Platform Investment}

Strategic choices include quality investment as well as prices. Under exclusivity, equilibrium strategies are given by: ${ }^{42}$

$$
\begin{array}{ll}
p_{A}^{e x c l}=t+\frac{3 t v \gamma}{9 t \gamma-2} ; & q_{A}^{e x c l}=\frac{1}{3 \gamma}+\frac{v}{9 t \gamma-2} \\
p_{B}^{e x c l}=t-\frac{3 t v \gamma}{9 t \gamma-2} ; & q_{B}^{e x c l}=\frac{1}{3 \gamma}-\frac{v}{9 t \gamma-2}
\end{array}
$$

giving equilibrium profits

$$
\begin{aligned}
& \pi_{A}^{e x c l}=\frac{1}{18 \gamma} \frac{(9 t \gamma-1)}{(9 t \gamma-2)^{2}}(9 t \gamma-2+3 v \gamma)^{2} \\
& \pi_{B}^{e x c l}=\frac{1}{18 \gamma} \frac{(9 t \gamma-1)}{(9 t \gamma-2)^{2}}(9 t \gamma-2-3 v \gamma)^{2}
\end{aligned}
$$

For the market to be competitive under exclusivity we require $9 t y-2 \geq 3 \mathrm{v} \gamma$.

Under non-exclusivity, equilibrium outcomes are symmetric with $p_{i}^{n e}=t+v$ and $q_{i}^{n e}=1 /(3 \gamma)$; market shares are equal. Equilibrium profits are then:

$$
\pi_{A}^{n e}=\frac{1}{2} t-\frac{1}{18 \gamma}+v ; \quad \pi_{B}^{n e}=\frac{1}{2} t-\frac{1}{18 \gamma} .
$$

Thus $A$ 's gain from exclusivity, $\pi_{A}^{e x c l}-\pi_{A}^{n e}$, is

$$
G_{q}=\frac{\gamma(9 t \gamma-1)}{2(9 t \gamma-2)^{2}} v^{2}-\frac{(18 t \gamma-5)}{3(9 t \gamma-2)} v .
$$

\section{University of Essex}

Submitted: 4 January 2012

Accepted: 22 July 2014

\footnotetext{
${ }^{42}$ Note that as $\gamma \rightarrow \infty$ (raising quality becomes prohibitively expensive), quality investment falls to zero and outcomes approach the static equilibrium of Section 1; i.e. this model encompasses the static model as the limiting case.
}

(C) 2014 The Authors.

The Economic Journal published by John Wiley \& Sons Ltd on behalf of Royal Economic Society. 


\section{References}

Anderson, S. and Coate, S. (2005). 'Market provision of broadcasting: a welfare analysis', Review of Economic Studies, vol. 72(4), pp. 947-72.

Armstrong, M. (1999). 'Competition in the pay-TV market', Journal of the Japanese and International Economies, vol. 13(4), pp. 257-80.

Autorité de la concurrence (2009). 'Avis sur les relations d'exclusivité entre activités d'opérateurs de communications électroniques et activités de distribution de contenus et de services', Avis No. 09-A-42, Paris, 7 July 2009.

Beggs, A. and Klemperer, P. (1992). 'Multi-period competition with switching costs', Econometrica, vol. 60(3), pp. 651-66.

Bourreau, M., Hombert, J., Pouyet, J. and Schutz, N. (2011). 'Upstream competition between vertically integrated firms', Journal of Industrial Economics, vol. 59(4), pp. 677-713.

Chen, Y. (2001). 'On vertical mergers and their competitive effects', Rand Journal of Economics, vol. 32(4), pp. $667-85$.

Chen, Y. and Riordan, M. (2007). 'Vertical integration, exclusive dealing, and ex post cartelization', Rand Journal of Economics, vol. 38(1), pp. 2-21.

Choi, J.P. and Yi, S.-S. (2000). 'Vertical foreclosure with the choice of input specifications', Rand Journal of Economics, vol. 31(4), pp. 717-43.

Competition Appeal Tribunal. (2012). 'Judgment in British Sky Broadcasting Ltd., Virgin Media Inc., The Football Association Premier League, British Telecommunications plc v. Office of Communications', Cases No. 1156-1159/8/3/10, London, 8 August 2012.

Crawford, G. and Yurukoglu, A. (2012). 'The welfare effects of bundling in multichannel television markets', American Economic Review, vol. 102(2). pp. 643-85.

Dukes, A. and Gal-Or, E. (2003). 'Negotiations and exclusivity contracts for advertising', Marketing Science, vol. 22(2), pp. 222-47.

Farrell, J. and Klemperer, P. (2007). 'Coordination and lock-in: competition with switching costs and network effects', in (M. Armstrong and R. Porter, eds.), Handbook of Industrial Organization: Vol. 3, pp. 1967-2072, Amsterdam: Elsevier North-Holland.

Gabszewicz, J., Laussel, D. and Sonnac, N. (2001). 'Press advertising and the ascent of the "pensée unique"?', European Economic Review, vol. 45(4-6), pp. 645-51.

Gabszewicz, J., Laussel, D. and Sonnac, N. (2002). 'Press advertising and the political differentiation of newspapers', Journal of Public Economic Theory, vol. 4(3), pp. 317-34.

Gabszewicz, J., Laussel, D. and Sonnac, N. (2004). 'Programming and advertising competition in the broadcasting industry', Journal of Economics and Management Strategy, vol. 13(4), pp. 657-69.

Gal-Or, E. and Dukes, A. (2003). 'Minimum differentiation in commercial media markets', Journal of Economics and Management Strategy, vol. 12(3), pp. 291-325.

Hagiu, A. and Lee, R. (2011). 'Exclusivity and control', Journal of Economics and Management Strategy, vol. 20 (3), pp. 679-708.

Harbord, D. and Ottaviani, M. (2001). 'Contracts and competition in the pay-TV market', Working Paper, London Business School.

Hart, O. and Tirole, J. (1990). 'Vertical integration and market foreclosure', Brookings Papers on Economic Activity (Microeconomics), pp. 205-85.

Hombert, J., Pouyet, J. and Schutz, N. (2010). 'Vertical integration, foreclosure, and upstream competition', Working Paper, Paris School of Economics.

Hotelling, H. (1929). 'Stability in competition', Economic Journal, vol. 39(1), pp. 41-57.

Jehiel, P. and Moldovanu, B. (2000). 'Auctions with downstream interactions among buyers', Rand Journal of Economics, vol. 31(4), pp. 768-91.

Jehiel, P., Moldovanu, B. and Stacchetti, E. (1996). 'How (not) to sell nuclear weapons', American Economic Review, vol. 86(4), pp. 814-29.

Kamien, M. and Tauman, Y. (1986). 'Fees versus royalties and the private value of a patent', Quarterly Journal of Economics, vol. 101(3), pp. 471-91.

Katz, M. and Shapiro, C. (1985). 'On the licensing of innovations', Rand Journal of Economics, vol. 16(4), pp. 504-20.

Katz, M. and Shapiro, C. (1986). 'How to license intangible property', Quarterly Journal of Economics, vol. 101 (3), pp. 567-89.

Lee, R. (2013). 'Vertical integration and exclusivity in platform and two-sided markets', American Economic Review, vol. 103(7), pp. 2960-3000.

Madden, P. and Pezzino, M. (2013). 'Sports league quality, broadcaster TV rights bids and wholesale regulation of sports channels', Working Paper, University of Manchester.

Nicita, A. and Rossi, M.A. (2008). 'Access to audio-visual contents, exclusivity and anticommons in new media markets', Communications and Strategies, vol. 71(3), pp. 79-101.

Ofcom (2007). 'Pay TV market investigation: consultation document', London, 18 December. 
Ofcom (2010). 'Pay TV statement', London, 31 March 2010.

Office of Fair Trading (2002). 'BSkyB investigation: alleged infringement of the Chapter II prohibition, decision of the Director General of Fair Trading'. Case No. CA98/20/2002, London, 17 December.

Ordover, J., Saloner, G. and Salop, S. (1990). 'Equilibrium vertical foreclosure', American Economic Review, vol. $80(1)$, pp. 127-42.

Ordover, J. and Shaffer, G. (2007). 'Wholesale access in multi-firm markets: when is it profitable to supply a competitor?', International Journal of Industrial Organization, vol. 25(5), pp. 1026-45.

Peitz, M. and Valletti, T. (2008). 'Content and advertising in the media: pay-TV versus free-to-air', International Journal of Industrial Organization, vol. 26(4), pp. 949-65.

Rey, P. and Tirole, J. (2007). 'A primer on foreclosure', in (M. Armstrong and R. Porter, eds.), Handbook of Industrial Organization: Vol. 3, pp. 2145-220, Amsterdam: Elsevier North-Holland.

Riordan, M. (1998). 'Anticompetitive vertical integration by a dominant firm', American Economic Review, vol. 88(5), pp. 1232-48.

Riordan, M. (2008). 'Competitive effects of vertical integration', in (P. Buccirossi, ed.), Handbook of Antitrust Economics, pp. 145-82, Cambridge, MA: MIT Press.

Salinger, M. (1988). 'Vertical mergers and market foreclosure', Quarterly Journal of Economics, vol. 103(2), pp. $345-56$.

Segal, I. (1999). 'Contracting with externalities', Quarterly Journal of Economics, vol. 114(2), pp. 337-88.

Shcherbakov, O. (2013). 'Measuring consumer switching costs in the television industry', Working Paper, University of Mannheim.

Stennek, J. (2014). 'Exclusive quality - why exclusive distribution may benefit the TV-viewers', Information Economics and Policy, vol. 26, pp. 42-57.

Ungerer, H. (2001). 'Introduction of competition in the communications market: the European experience', speech given at Plano Editorial, Rio de Janeiro, 20 September 2001.

Weeds, H. (2014). 'Advertising and the distribution of content', Working Paper, University of Essex. 